\title{
Revalidation of Enteromius alberti and presence of Enteromius cf. mimus (Cypriniformes: Cyprinidae) in the Lake Edward system, East Africa
}

\author{
Heleen MAETENS ${ }^{1, *}$, Maarten VAN STEENBERGE ${ }^{2}$, Jos SNOEKS $^{3}$ \& Eva DECRU ${ }^{4}$ \\ ${ }^{1,2,3,4}$ Section Vertebrates, Biology Department, Royal Museum for Central Africa, \\ Leuvensesteenweg 13, 3080 Tervuren, Belgium. \\ ${ }^{2,3,4}$ Laboratory of Biodiversity and Evolutionary Genomics, Department of Biology, \\ University of Leuven, Ch. Deberiotstraat 32, 3000 Leuven, Belgium. \\ ${ }^{2}$ Operational Directorate Taxonomy and Phylogeny, Royal Belgian Institute of Natural Sciences, \\ Vautierstraat 29, 1000 Brussels, Belgium. \\ ${ }^{2}$ Masaryk University, Department of Botany and Zoology, Kotlářská 2, 61137 Brno, Czech Republic. \\ *Corresponding author: heleen.maetens@africamuseum.be \\ ${ }^{2}$ Email: maarten.vansteenberge@naturalsciences.be \\ 33Email: jos.snoeks@africamuseum.be \\ ${ }^{4}$ Email: eva.decru.icht@gmail.com

\footnotetext{
${ }^{1}$ urn:1sid:zoobank.org:author:6DBEE3D3-FAC8-438D-B937-54728E17CD1F

${ }^{2}$ urn:lsid:zoobank.org:author:57C714E0-F233-4B3E-960E-17A7863FBF6F

${ }^{3}$ urn:1sid:zoobank.org:author:13A8AB26-FF46-437C-9806-D49E11C5E15D

${ }^{4}$ urn:1sid:zoobank.org:author:1AEB7EED-C939-4702-8590-B3FCA7076324
}

\begin{abstract}
A revision was done on the species of Enteromius Cope, 1867 (Cypriniformes: Cyprinidae) from the Lake Edward system with a smooth, flexible third unbranched dorsal fin ray without serrations. Specimens with these characteristics had previously been attributed to E. perince and E. stigmatopygus. A combination of a genetic (COI, mtDNA) and a morphometric approach was used. Based on the COI gene, we found two groups with a distance of $8.5 \%$, though neither of the two corresponded to E. perince or E. stigmatopygus. One group revealed to be conspecific with E. alberti, previously a synonym of E. stigmatopygus, described from the Rutshuru River, May-Ya-Moto (DRC, Lake Edward system), and revalidated here. In addition, E. cercops, described from the Nzoia River (Kenya, Lake Victoria basin), is put in synonymy with $E$. alberti. The second group was most similar to E. mimus, but differed morphologically somewhat from the types of $E$. mimus. Therefore, specimens of this group were identified as E. cf. mimus. Morphologically, E. alberti can be separated from E. cf. mimus based on a higher number of lateral line scales and smaller values for interorbital width, pre-pelvic distance, body depth, maximum and minimum caudal peduncle depth, head width and head depth.
\end{abstract}

Keywords. Enteromius cercops, Enteromius perince, Enteromius stigmatopygus, integrative taxonomy, synonymy. 
Maetens H., Van Steenberge M., Snoeks J. \& Decru E. 2020. Revalidation of Enteromius alberti and presence of Enteromius cf. mimus (Cypriniformes: Cyprinidae) in the Lake Edward system, East Africa. European Journal of Taxonomy 700: 1-28. https://doi.org/10.5852/ejt.2020.700

\section{Introduction}

With an estimated 367 genera and 3006 species, Cyprinidae is the largest family of freshwater fishes in the world (Nelson et al. 2016). One of these genera, Enteromius Cope, 1867, occurs only on the African continent and contains about 211 valid species, making it the second largest fish genus in Africa, and the third largest in the world, only exceeded by Schistura McClelland, 1838 (228 valid species), and Haplochromis Hilgendorf, 1888 (229 valid species) (Froese \& Pauly 2019). The genus Enteromius, formerly referred to as 'Barbus' (Berrebi et al. 1996), represents a non-monophyletic group that includes most small-sized African diploid barbs (Yang et al. 2015; Hayes \& Armbruster 2017).

\section{Taxonomic problems in the genus Enteromius}

There is a general opinion among ichthyologists that cyprinids are a taxonomically difficult group and that many species 'look the same', having a rather uniform body shape (Lowe-McConnell 1975; Howes 1991). This specifically holds for Enteromius. Specimens of this genus can be attributed to three groups based on the morphology of the third unbranched dorsal fin ray: bony with serrations, bony without serrations, or slender and flexible without serrations (Skelton et al. 1991). While these characters seem to be indicative of a common descent on a small geographic scale, as demonstrated in studies on the species from the basins of the Congo River (Van Ginneken et al. 2017) and of Lake Edward (Decru et al. 2019), on a larger geographic scale, they do not seem to give a reliable phylogenetic signal (Yang et al. 2015; Ren \& Mayden 2016; Hayes \& Armbruster 2017), and point at convergent evolution at higher levels of hierarchy in the trees. Furthermore, the identification of species of Enteromius is challenging because of morphological similarities, a limited representation in the literature and because of a lack of identification keys and large-scaled revisions (Van Ginneken et al. 2017; Decru et al. 2019). Consequently, many specimens in museum collections, as well as the voucher specimens of several sequences on GenBank are misidentified (Hayes \& Armbruster 2017). In addition to the paucity of taxonomic data, recent studies on species of Enteromius from various regions revealed the presence of many undescribed species (Schmidt et al. 2017; Van Ginneken et al. 2017). This also implies that the species diversity in Enteromius might be of an even much larger magnitude than currently thought. Indeed, if these findings of hidden diversity can be extrapolated to other regions, then an enormous increase of species numbers among the small African barbs is to be expected, which could render Enteromius the by far most species-rich, although currently nonmonophyletic, fish genus in the world.

It is intriguing to find these small, inconspicuous fish to be so hyperdiverse. However, the mechanisms driving speciation in Enteromius have never been investigated. The study of Van Ginneken et al. (2017) on some groups of Enteromius from the Congo basin, suggested a mainly allopatric mode of speciation, as most lineages are confined to a certain river stretch. Allopatric speciation is probably the mode of speciation by which the majority of riverine fishes arose (Seehausen \& Wagner 2014). Still, in the case of Enteromius, it is difficult to envisage how allopatric speciation alone can explain some cases of morphological highly similar species occurring in sympatry, as was found in the study of Van Ginneken et al. (2017). Furthermore, hybridisation events can also be important in the evolutionary history of Enteromius. This has already been documented for several cichlid and cyprinid lineages in Africa (Schwarzer et al. 2012; Wagner et al. 2012; Levin et al. 2017) and specifically for Enteromius, Schmidt et al. (2017) found cases of introgression in some Kenyan species. 


\section{Species of Enteromius from the Lake Edward system}

The Lake Edward system is situated on the border between the Democratic Republic of the Congo (DRC) and Uganda. The system includes Lake Edward (surface area: $2325 \mathrm{~km}^{2}$ ), which is one of the smaller East African Great Lakes, Lake George (surface area: $250 \mathrm{~km}^{2}$ ), the Kazinga Channel, which connects both lakes, and several inflowing rivers and isolated crater lakes. The system is situated in High Africa (sensu Roberts 1975), the southern and eastern part of the African continent that lies almost completely above 300 meters. The rivers in High Africa are characterized by having a poor fish fauna that is dominated by Cyprinidae (Roberts 1975; Skelton 1994). This especially holds for the rivers of the Lake Edward system, where Enteromius is mainly found (Decru et al. 2019). However, not much information is available on the physiochemical characteristics of these rivers (Mbalassa et al. 2014). The system is situated at the limit of three ichthyofaunal provinces as described by Roberts (1975): the Nilo-Sudan, the Congo and the EastCoast Provinces. Initially, the system was assigned to the Nilo-Sudan Province (Roberts 1975). However, in a recent study on the fish fauna of the Lake Edward system, it was shown that the Lake Edward system has more affinity with the East-Coast ichthyofaunal Province (Decru et al. 2019), confirming the previous assignment of the basin to this province (Snoeks et al. 2011).

In the most recent checklist of the ichthyofauna of the Lake Edward system (Decru et al. 2019), five species of Enteromius were listed: E. apleurogramma (Boulenger, 1911), E. kerstenii (Peters, 1868), E. pellegrini (Poll, 1939), E. perince (Rüppell, 1835) and E. stigmatopygus (Boulenger, 1903). In that study, the need of a revision of these species was already underscored. Enteromius apleurogramma, E. kerstenii and E. pellegrini all have a bony and serrated third unbranched dorsal fin ray. These species were described from localities in the East Coast Province outside the Lake Edward system. Enteromius perince and E. stigmatopygus, both with a smooth third unbranched dorsal fin ray, were described from the Nile in Egypt and the White Nile in Sudan, respectively. This renders E. perince and E. stigmatopygus, together with Labeo forskalii Rüppell, 1835, the only fish species from the Lake Edward system that are not shared with other systems of the East Coast Province, but only with the Nile system within the NiloSudan Province (Decru et al. 2019). In contrast, the remaining species of Enteromius, as well as most other small-sized riverine fishes, are shared with other systems within the East Coast Province and are absent from the Nile. This disparity probably implies an underlying taxonomic problem.

In his review of the Nilotic small barbs, Banister (1987) listed both E. perince and E. stigmatopygus, but noted that they were difficult to distinguish from each other. Boulenger (1903) reported in the original description of E. stigmatopygus that only the anterior scales of the lateral line are pored. Banister (1987), however, mentioned that the number of pored scales along the lateral line is not a good characteristic to distinguish E. stigmatopygus from other species. The specimens of the type series of E. stigmatopygus are small and he found that the pores start to develop when specimens become larger. The same applies to the development of the barbels. Boulenger (1903) mentioned the absence of barbels in E. stigmatopygus. However, Banister (1987) found posterior barbels in the larger type specimens. In addition, he stated that the classification of Enteromius relies too much on the number of barbels. In the same study, Banister (1987) mentioned some other characters to distinguish E. stigmatopygus from other species. He found E. stigmatopygus to be more 'spotted' than E. perince, and adult specimens to differ from spotted specimens of $E$. perince in the more anterior position of the middle spot. Additionally, according to the description by Banister (1987), E. perince has seven well-developed gill rakers on the first ceratobranchial, while E. stigmatopygus has only two that are situated on the dorsal part of the first ceratobranchial and papillate tissue (see Banister 1987: 123, fig. 12) on the ventral part. In the same publication, when redescribing E. stigmatopygus, he mentioned two to four large gill rakers on the dorsal part and papillate tissue with zero to three low ridges of unknown homology on the ventral part of the first ceratobranchial. Banister (1987) also put E. alberti (Poll, 1939), described from the Rutshuru River, May-Ya-Moto (DRC), situated in the southern part of the Lake Edward system, in synonymy with E. stigmatopygus. He did this without examining the type specimens of E. alberti. 
During four recent expeditions to the Lake Edward system (2016-2019, Decru et al. 2019), several specimens resembling E. stigmatopygus and E. perince were collected. It was, however, not possible to assign the specimens to either of these two species, based on the diagnostic characters proposed by Banister (1987). In our study, the E. stigmatopygus / perince-like specimens were examined using an integrative approach in order to evaluate their taxonomic status, and to assign them to the correct species.

\section{Material and methods}

During the HIPE project (Human impacts on ecosystem health and resources of Lake Edward), four field expeditions to the Ugandan side of the Lake Edward system took place, three during the wet (October 2016, March 2017, March 2019) and one during the dry (January 2018) season. The Congolese side of the system was not sampled due to security issues. Specimens of Enteromius were caught using gillnets with different mesh sizes, scoop nets and a backpack electrofisher. After euthanasia with clove oil, for some specimens, a tissue sample (fin clip) was taken for molecular analyses and stored in $100 \%$ ethanol. Specimens were then fixed in formalin. At the RMCA (Royal Museum for Central Africa), specimens were rinsed and transferred to $70 \% \mathrm{EtOH}$. For morphological analyses, specimens of the first three expeditions were used and specimens of all four expeditions were used for genetic analyses.

In total, we examined 214 specimens, 72 of which both genetically and morphometrically, 70 specimens only genetically and 72 specimens only morphologically (Supplementary File SM.01). The latter group included the type specimens of E. perince, E. stigmatopygus and of E. alberti, as well as four specimens from a marshy area near Tshambi, identified as E. alberti, and mentioned in the original description of E. alberti. One of these specimens was too small to take correct measurements of and consequently was excluded from the analyses. The syntypes of E. mimus (Boulenger, 1912) and the holotype and seven paratypes of E. cercops (Whitehead, 1960) were also examined morphometrically. These species, which stem from other parts of the East Coast and the Nile system (i.e., the regions that border to the Lake Edward system), are most similar to the specimens of E. stigmatopygus/perince from Lake Edward, and were therefore included in the morphometric study. From the ten syntypes of E. mimus, one was not conspecific with the others because it had serrations on the third unbranched dorsal fin ray and it was the only specimen without a clear melanin pattern. Hence it was not included in our analyses. A lectotype was assigned for E. alberti and E. mimus in this study.

\section{DNA extraction, PCR amplification and sequencing, DNA analyses}

DNA was extracted from finclips using a 'NucleoSpin ${ }^{\circledR}$ Tissue Kit' using the standard protocol for human or animal tissue and cultured cells (Macherey-Nagel, Germany). The mitochondrial cytochrome c oxidase I (COI) gene was isolated and amplified using the M13-tailed primer cocktail of Ivanova et al. (2007) and the protocol of Decru et al. (2016), but using 2.0 instead of $1.0 \mu 1$ extracted DNA. Amplified PCR products were visualised on 1.2\% agarose gels and afterwards purified using ExoSAP (Fermentas). The sequences were determined in two directions, forward and reverse, by Sanger sequencing, executed by the external company Macrogen. The DNA sequences were assembled and visually checked in CodonCode Aligner 4.2.7 (CodonCode Corporation). The consensus sequences were aligned in MEGA 7.0.26 (Kumar et al. 2016) and the primer sequences were deleted. A TCS haplotype network (Templeton et al. 1992) was generated using PopART (Leigh \& Bryant 2015) to visualise the haplotype pattern and to examine geographic structuring. Clusters were identified in the TCS-network, based on genetic differences between the haplotypes.

We searched for COI sequences on GenBank (Clark et al. 2016) of specimens, identified as one of the species examined in this study, in order to compare them with our COI sequences from the Lake Edward system (Supplementary File SM.01). Only five sequences of E. perince (LC487172.1 - LC487176.1) from El-Kanater station, northern part of the Nile River, Egypt (Dr Fawzia Salah Ali pers. com.) were 
available (Supplementary File SM.01) (voucher specimens are stored in the National Institute For Oceanography \& Fisheries (NIOF), Alexandria, Egypt). The genetic divergence between our sequences and those from GenBank has been assessed.

\section{Morphometric analyses}

Twenty-four morphometric measurements were taken with a dial caliper and 13 meristics were counted on each specimen. Most measurements and all counts were done under a binocular microscope (Wild Heerbrugg M3). Measurements were based on Bamba et al. (2011) with some modifications. Post-dorsal distance I, post-anal distance I and body depth I were not measured, because of the strong correlation with other measurements. The following measurements were added: head width (width of the head at the level of the posterior margin of the pre-operculum), head depth (depth of the head at the level of the posterior occipital margin), anal fin base length (distance between the articulation base of the first and last anal fin rays), anal fin length (distance from the articulation of the first anal fin ray to the tip of the longest anal fin ray), pectoral fin length (distance from the articulation of the first pectoral fin ray to the tip of the longest pectoral fin ray) and pelvic fin length (distance from the articulation of the first pelvic fin ray to the tip of the longest pelvic fin ray). For all meristics, Bamba (2012) was followed.

The multivariate dataset was explored by Principal Component Analyses (PCA) to reduce the large number of variables into a few meaningful axes that are linear combinations of the original variables (Manly 1994; Snoeks 2004; Decru et al. 2012). Measurements and meristics were analysed separately. Log-transformed data were used for the PCA on the measurements and analysed with a covariance matrix. The first axis of the PCA on log-transformed measurements can be interpreted as a proxy for size (Bookstein et al. 1985). Hence, subsequent axes can be plotted against the first axis to verify possible size effects. The raw data were used for the PCA on the meristics based on the correlation matrix. Invariable meristics were excluded from the PCAs. Data for the barbels were not included in the analyses, as the barbels were small and difficult to measure and hence their measurements were prone to errors.

A first PCA was performed on the 72 specimens from the Lake Edward system that were analysed genetically to evaluate the morphological differences among specimens from different genetic clades. To find possible significant differences between these groups, univariate comparisons were performed with non-parametric Mann-Whitney U-tests (MWU), with sequential Bonferroni corrections (Rice 1989). For measurements, these comparisons were restricted to subsets of specimens that belong to a similar size class $(46.4-53.8 \mathrm{~mm} \mathrm{SL}$; with $\mathrm{p}=0.6888$ for $\mathrm{SL})$. This was done to avoid allometric interference. Scatterplots of individual measurements (\% SL) were made to visualize between-group differences taken into account possible size-effects. Based on this first set of analyses, additional specimens for which no genetic data were available, were measured and assigned to one of the groups in order to enlarge the size ranges of these groups. This also allowed for comparison with the type series of similar species. Hence, in a second series of analyses, PCAs were performed to compare each group separately with all of the studied type specimens of E. perince, E. stigmatopygus, E. alberti, E. mimus and E. cercops, and with the specimens from Tshambi identified as E. alberti.

The statistical analyses were executed in R Studio 1.1.453 (RStudio Team 2016) with R ver. 3.5.1 (R Core Team 2018). Scatterplots and PCAs were made using the package 'vegan' ver. 2.5-2 (Oksanen et al. 2018) and the package 'factoextra' ver. 1.0.5 (Kassambara \& Mundt 2017).

\section{Results}

We successfully obtained 137 COI sequences (trimmed to 651 bp) (Supplementary File SM.01). The haplotype network of the specimens from the Lake Edward system (Fig. 1) showed two clear groups with a genetic divergence of $8.5 \%$. No geographical structuring was observed. We refer to these groups as group $A$, the smallest group $(n=36)$, and group $B$, the largest group $(n=101)$. The sequences of 


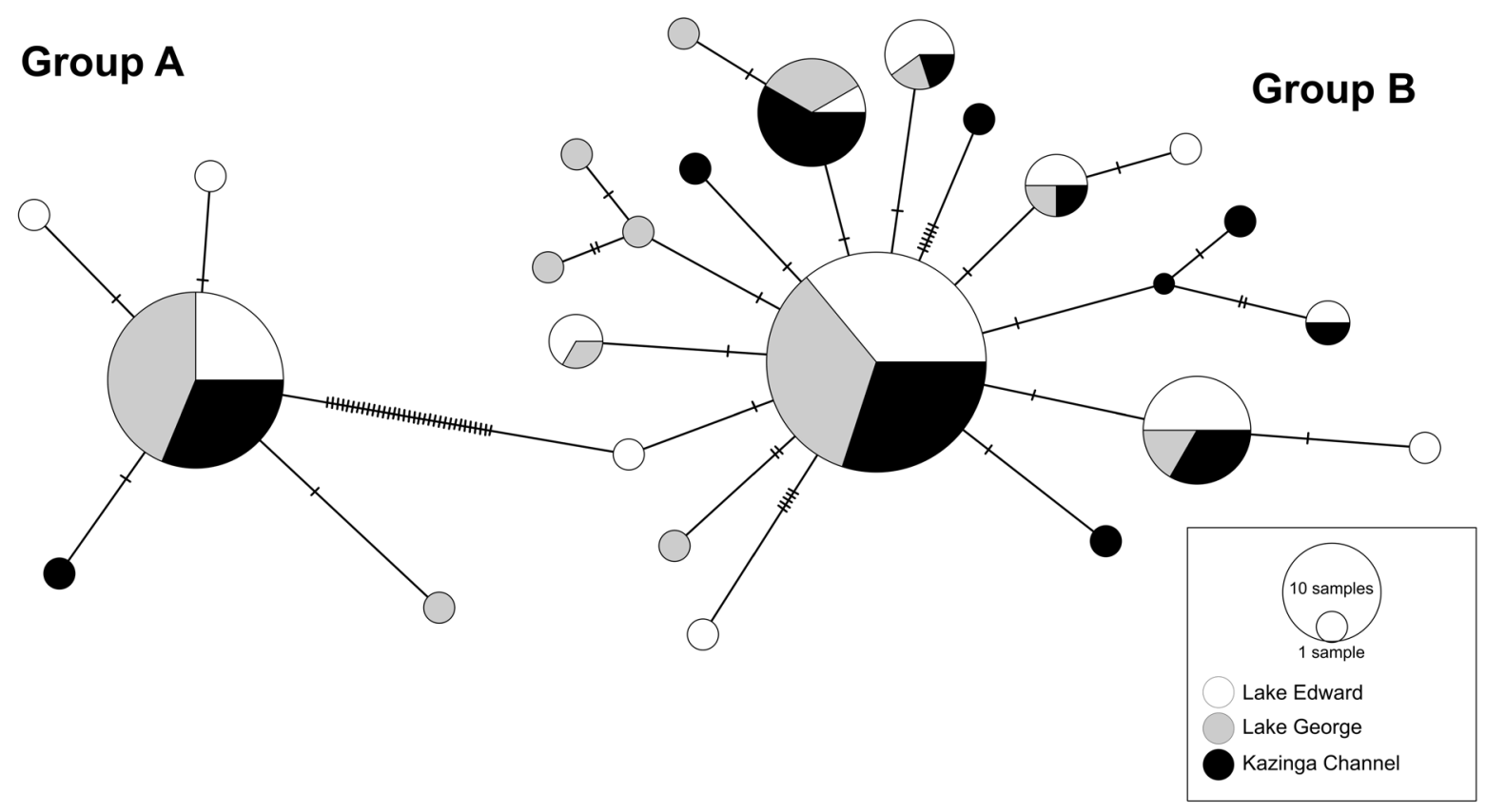

Fig. 1. Haplotype network of 651-bp-long COI sequences $(n=137)$ of the specimens of Enteromius Cope, 1867 with a smooth, flexible last unbranched dorsal fin ray from the Lake Edward system. Each circle represents a haplotype, with the size of the circles indicating the number of individuals with this haplotype and the colour indicating the different parts of the basin. Each bar represents a mutation between two haplotypes.

E. perince from Egypt, obtained from GenBank, had a genetic difference of $12 \%$ from the sequences of our groups A and B, and were therefore not integrated in the haplotype network.

\section{Morphometric analyses}

Of the 137 specimens that were analysed genetically, 71 specimens were also analysed morphometrically. A first PCA on the log-transformed measurements of these specimens resulted in a separation on PC2 (Fig. 2) of the two groups that were delineated based on the genetic data. PC1 represented an inverted proxy of size, with larger specimens having lower values on PC1 than smaller specimens. The most important loadings for PC2 were for the post-anal distance and the maximum and minimum caudal peduncle depth (Supplementary File SM.02). In the PCA on meristics, the two groups partially overlapped (not illustrated).

Based on Mann-Whitney U (MWU) tests with sequential Bonferroni correction, 13 measurements and three meristics were significantly different between the two groups, of which the three meristics were highly significant (Table 1). Individual scatterplots were made for the most significant measurements (\% SL) (Fig. 3): interorbital width, pre-pelvic distance, body depth, maximum caudal peduncle depth, minimum caudal peduncle depth, head width, and head depth. For all of these measurements, the ranges per se overlapped because of allometry, but for specimens of similar size classes, the two groups could be distinguished from each other, with specimens of group B having higher values for all these measurements. Based on the results of the first series of analyses discussed above, we were able to identify 16 additional specimens as members of group A, and 22 additional specimens as members of group B. These specimens were added to the dataset to enlarge the size ranges of the two groups, allowing for a better comparison of the groups with the type series of the relevant species. Subsequently, each 
Table 1. Results of the MWU tests with Bonferroni correction on measurements (\% SL) of specimens of similar size classes (46.4-53.8 mm), and on meristics of all specimens, on the two groups of Enteromius Cope, 1867. Significant values $(\alpha=0.05)$ are in bold; highly significant values $(\alpha=0.001)$ are in bold and underlined.

\begin{tabular}{|c|c|}
\hline Measurements (\% SL) & Group A $(n=8) \times$ Group B $(n=10)$ \\
\hline Head length (HL) & 0.0831 \\
\hline Eye diameter (ED) & 0.0029 \\
\hline Snout length (SnL) & 0.0062 \\
\hline Pre-operculum distance (PrOpD) & 0.0155 \\
\hline Interorbital width (IOW) & $<0.0001$ \\
\hline Pre-dorsal distance (PrDD) & 0.0044 \\
\hline Post-dorsal distance (PoDD) & 0.0002 \\
\hline Dorsal fin base length (DoFBL) & 0.5726 \\
\hline Dorsal fin lenght (DoFL) & 0.3599 \\
\hline Pre-pectoral distance (PrPecD) & 1.0000 \\
\hline Pre-pelvic distance (PrPelD) & $<0.0001$ \\
\hline Pre-anal distance (PrAD) & 0.0014 \\
\hline Post-anal distance (PoAD) & 0.0009 \\
\hline Body depth (BD) & $<0.0001$ \\
\hline Maximum caudal peduncle depth (MxCPD) & $<0.0001$ \\
\hline Minimum caudal peduncle depth (MnCPD) & $<0.0001$ \\
\hline Pre-occipital distance (PreOcD) & 0.0343 \\
\hline Head width (HW) & $<0.0001$ \\
\hline Anal fin base length (AnFBL) & 0.0205 \\
\hline Anal fin length (AFL) & 0.0009 \\
\hline Pectoral fin length (PcFL) & 0.5726 \\
\hline Pelvic fin length (PlvFL) & 0.4082 \\
\hline Head depth (HD) & $<0.0001$ \\
\hline Meristics & Group A $(n=22) \times$ Group B $(n=50)$ \\
\hline Lateral line scales (LLS) & $\leq 0.0001$ \\
\hline Total number of lateral line scales (LLS total) & $\leq 0.0001$ \\
\hline Pre-dorsal scales (PDSc) & 0.0266 \\
\hline Scales lateral line - pelvic fin (LPSc) & 0.1268 \\
\hline Scales lateral line - belly (L-BSc) & 0.2653 \\
\hline Branched dorsal fin rays (DFR branched) & 0.1303 \\
\hline Branched anal fin rays (AFR branched) & 0.1450 \\
\hline Branched pectoral fin rays (PecFR branched) & $\leq 0.0001$ \\
\hline Unbranched pelvic fin rays (PelFR unbranched) & 0.4942 \\
\hline Branched pelvic fin rays (PelFR branched) & 0.6916 \\
\hline Gill rakers upper limb first gill arch (GrUp) & 0.6935 \\
\hline Gill rakers lower limb first gill arch (GrLow) & 0.8736 \\
\hline Total gill rakers (GrTot) & 0.7320 \\
\hline
\end{tabular}




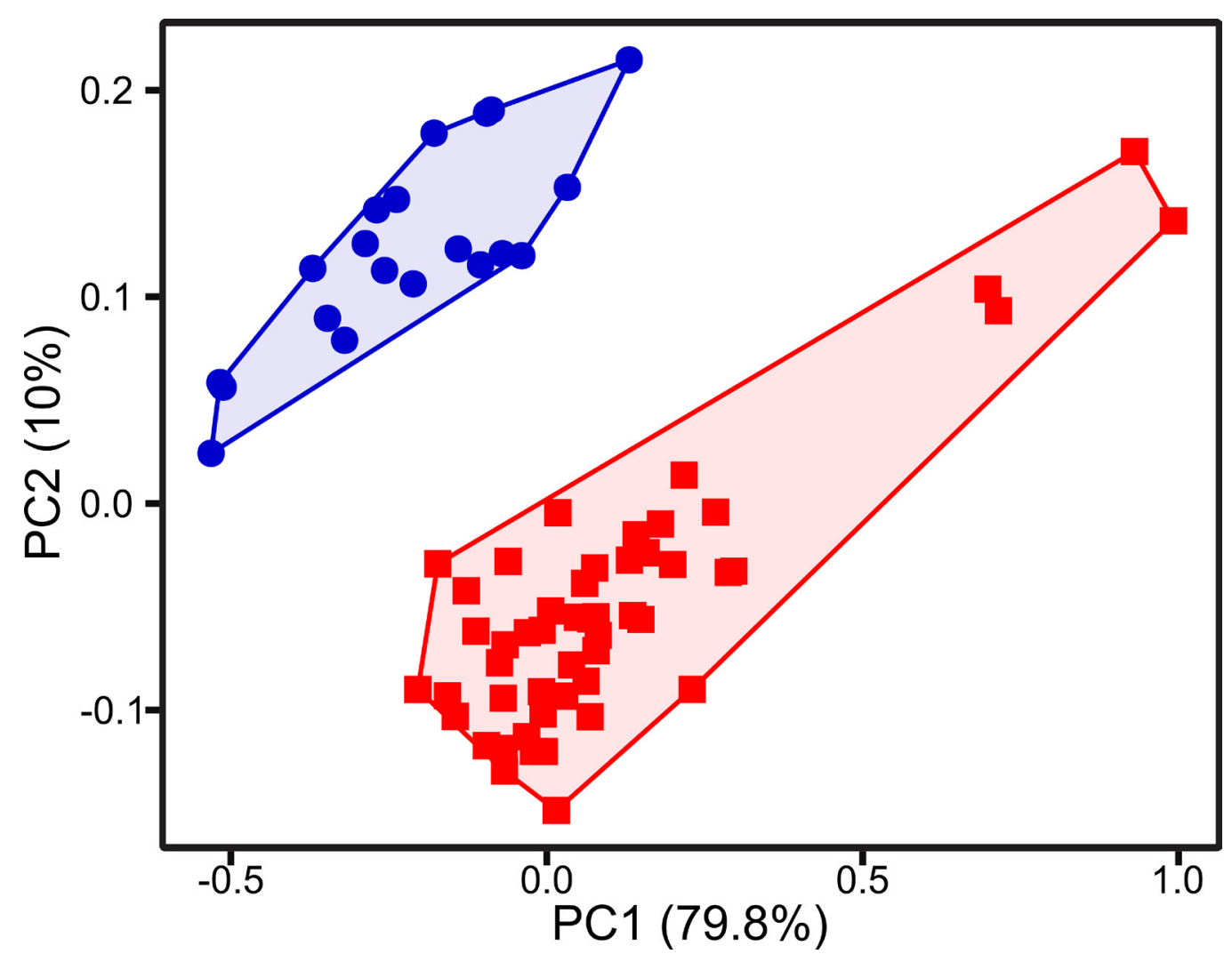

Fig. 2. Scatterplot of $P C 2$ against $P C 1$ of a PCA on 24 log-transformed measurements on 71 specimens of Enteromius Cope, 1867. Specimens of the genetic groups A $(\bullet)(\mathrm{n}=21)$ and B $(\square)(\mathrm{n}=50)$ are indicated separately.

group was compared with the types of E. alberti, E. cercops, E. mimus, E. perince and E. stigmatopygus and the additional specimens from Tshambi identified as E. alberti.

A PCA on log-transformed measurements was performed on the specimens assigned to group A, all the type specimens included in this study and the specimens from Tshambi (Fig. 4a). On a scatterplot of PC2 vs $\mathrm{PC} 1$, specimens belonging to group A were separated from E. perince, E. stigmatopygus and the specimens from Tshambi. They were also separated from the types of E. mimus, except for one specimen. The holotype and paratypes of E. cercops and two of the three types of E. alberti fell, however, into the polygon of group A. The most important loadings for PC2 were the maximum caudal peduncle depth, the interorbital width and the body depth (Supplementary File SM.03).

In a scatterplot of the two main PCs of a PCA on the meristics, the type specimens of $E$. alberti fell within group A and E. cercops overlapped with group A (Fig. 4b). Here, group A also partially overlapped with $E$. perince, due to one specimen, but it was completely separated from the specimens from Tshambi, E. mimus and E. stigmatopygus on PC1. The most important loadings for PC1 were the number of scales on the lateral line, the number of branched pectoral fin rays and the number of scales between the origin of the dorsal fin and the lateral line (Supplementary File SM.04). As the specimens from Tshambi, identified as E. alberti, fell separately from the types of E. alberti, these were most probably misidentified. To explore possible differences between group A, E. alberti and E. cercops, subsequent PCAs were performed restricted to these three groups. In these analyses, still no separation of the three groups was obtained (not illustrated). 
(a)

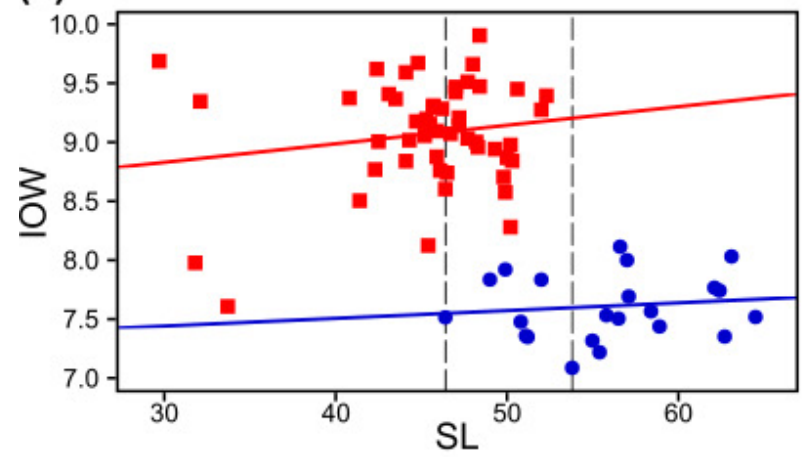

(c)

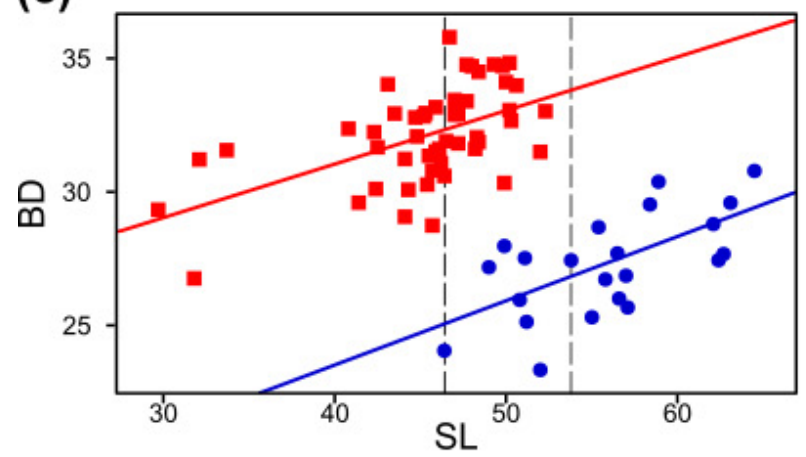

(e)

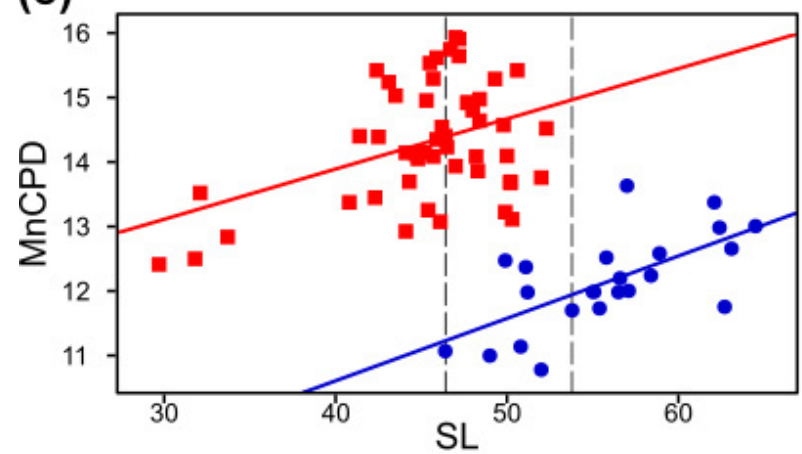

(g)

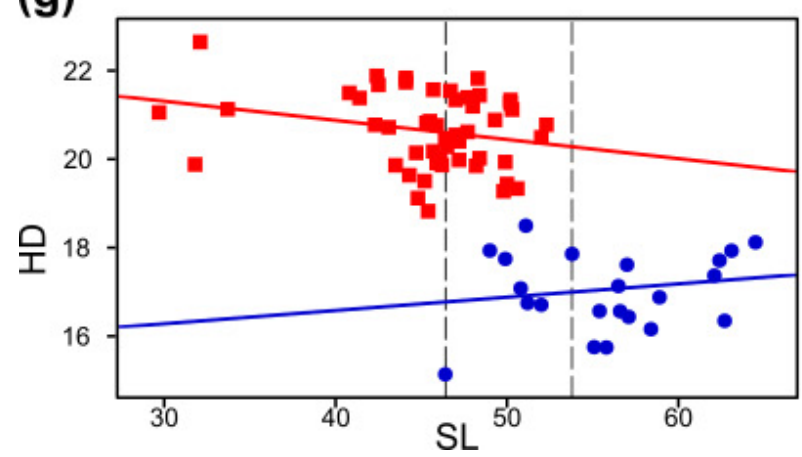

(b)

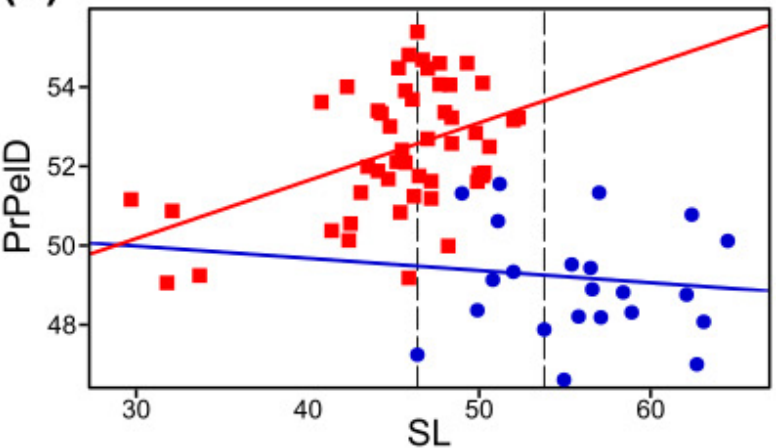

(d)

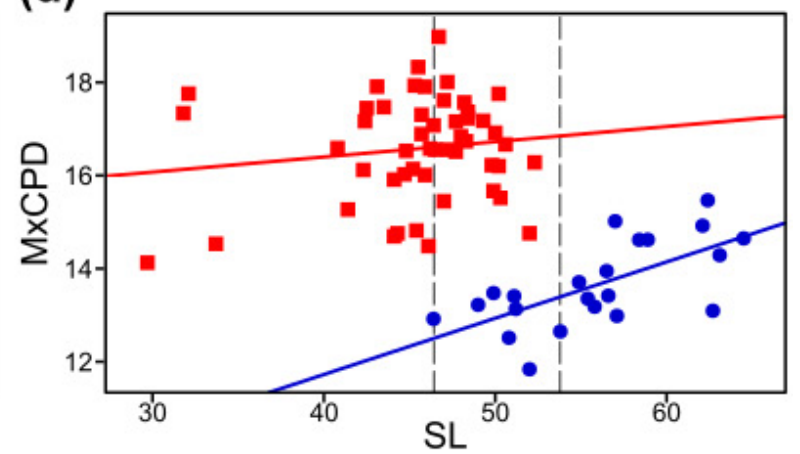

(f)

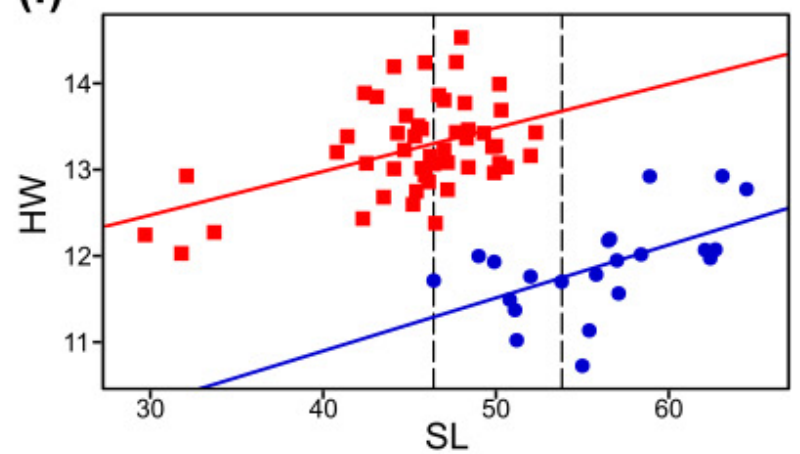

Fig. 3. Scatterplots of (a) interorbital width (IOW), (b) pre-pelvic distance (PrPelD), (c) body depth (BD), (d) maximum caudal peduncle depth (MxCPD), (e) minimum caudal peduncle depth (MnCPD), (f) head width (HW), and (g) head depth (HD) in \% SL against SL (in mm) on 72 specimens of Enteromius Cope, 1867. The genetic groups A $(\bullet)(n=22)$ and B $(\bullet)(n=50)$ are indicated separately. The dashed lines indicate the size class used for the MWU tests. 

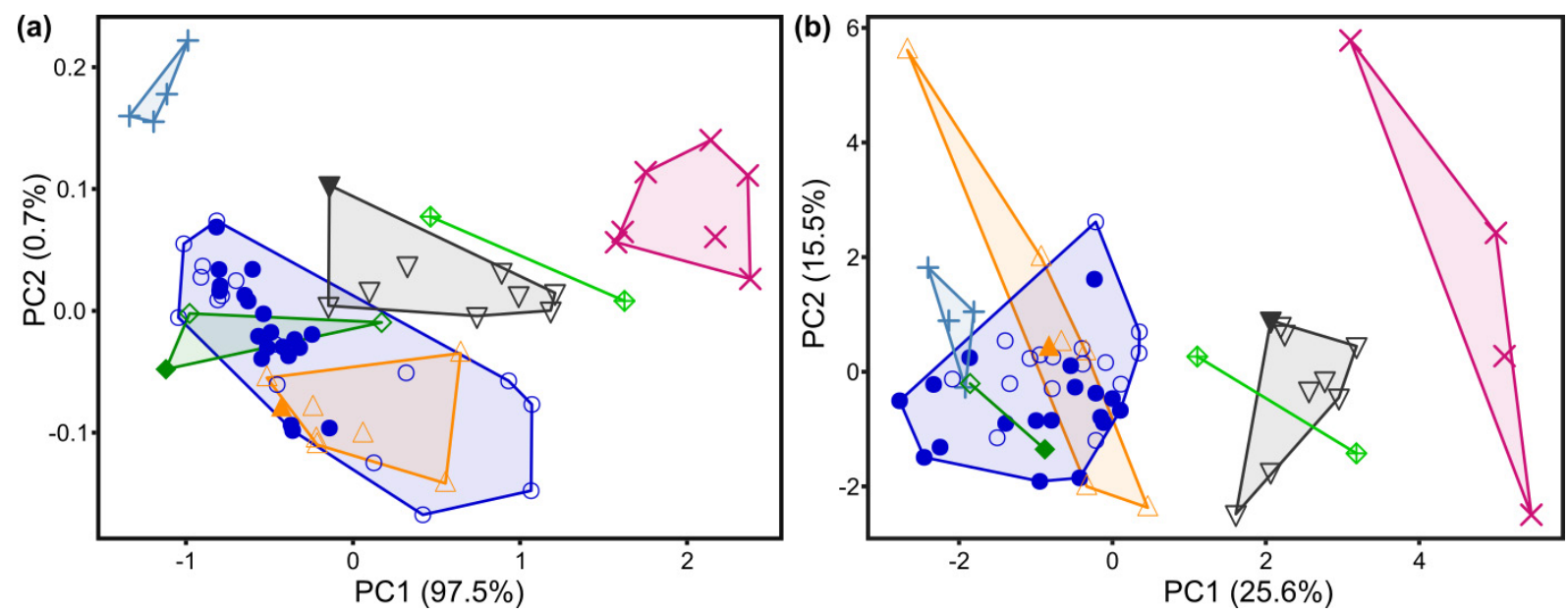

Fig. 4. Scatterplots of $\mathrm{PC} 2$ against $\mathrm{PC} 1$ of the PCA on (a) 24 log-transformed measurements $(n=69)$ and (b) on 15 meristics $(n=62)$. Specimens of group A, the filled circles $(\bullet)$ represent the genetically analysed specimens, the open circles $(\odot)$ indicate the additional specimens. Specimens of E. alberti (Poll, 1939) (lectotype) $(\diamond)$, E. alberti (paralectotypes) $(\diamond)$, specimens from Tshambi $(\bullet)$, E. cercops (Whitehead, 1960) (holotype) ( $\triangle$ ), E. cercops (paratypes) $(\triangle)$, E. mimus (Boulenger, 1912) (lectotype) ( $\mathbf{\nabla})$, E. mimus (paralectotypes) $(\nabla)$, E. perince (Rüppell, 1835) (syntypes) $(+)$ and E. stigmatopygus (Boulenger, 1903) (syntypes) $(\times)$.
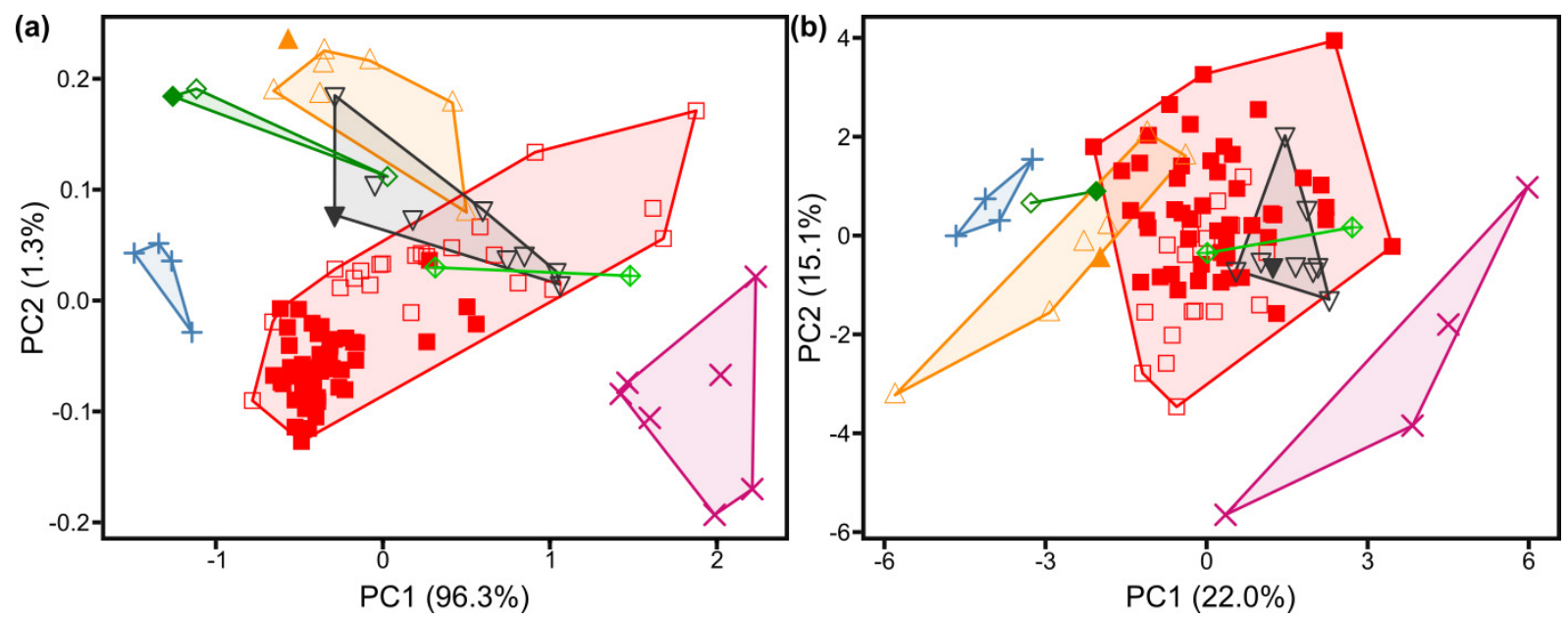

Fig. 5. Scatterplots of $\mathrm{PC} 2$ against $\mathrm{PC} 1$ of (a) the PCA $(\mathrm{n}=105)$ on 24 log-transformed measurements and (b) the PCA $(\mathrm{n}=95)$ on 15 meristics. Specimens of group B, the filled squares $(\square)$ represent the genetic analysed specimens, the open squares $(\square)$ indicate the additional specimens. Specimens of $E$. alberti (Poll, 1939) (lectotype) ( $\diamond)$ E. alberti (paralectotypes) $(\diamond)$, specimens from Tshambi $(\diamond)$, E. cercops (Whitehead,

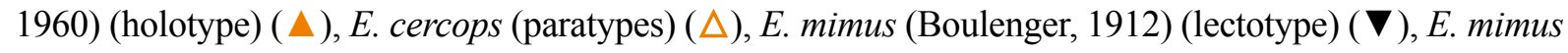
(paralectotypes) $(\nabla)$, E. perince (Rüppell, 1835) (syntypes) $(+)$ and E. stigmatopygus (Boulenger, 1903) (syntypes) $(\times)$. 
Specimens belonging to group B were also compared with the type specimens of the selected species and the specimens from Tshambi. In the PCA on the log-transformed measurements, group B was separated from most of the type specimens, but partially overlapped with those of E. mimus and with one paratype of E. cercops on PC2 for specimens with similar sizes (Fig. 5a). Furthermore, one of the specimens from Tshambi was situated within the polygon of group B, while the other one was located just outside of the polygon. The most important loadings for PC2 were the anal fin base length, the interorbital width and the anal fin length (Supplementary File SM.05).

Another PCA was performed on the meristics of group B and the selected type specimens. Here, both specimens from Tshambi fell within group B. Almost all types of E. mimus were situated within the polygon of group B, except for one, which was located just outside of the polygon. Group B partially overlapped with E. cercops (Fig. 5b). The most important loadings for PC1 were the number of scales on the lateral line, around the caudal peduncle and below the lateral line and, for PC2, the total number of gill rakers, the number of gill rakers on the lower part of the first gill arch and the number of pre-dorsal scales (Supplementary File SM.06).

These PCAs (Fig. 5) illustrated that the specimens from Tshambi, identified as E. alberti, were most probably conspecific to our group B. This latter group seemed to be most similar to E. mimus. Therefore, additional PCAs on meristics and log-transformed measurements were performed including only group $\mathrm{B}$, with the inclusion of the specimens from Tshambi, and the types of E. mimus. For the meristics, the syntypes of E. mimus fell completely within the range of group B for the first two axes (not illustrated). For the log-transformed measurements, however, only a partial overlap was observed on PC2 (Fig. 6).

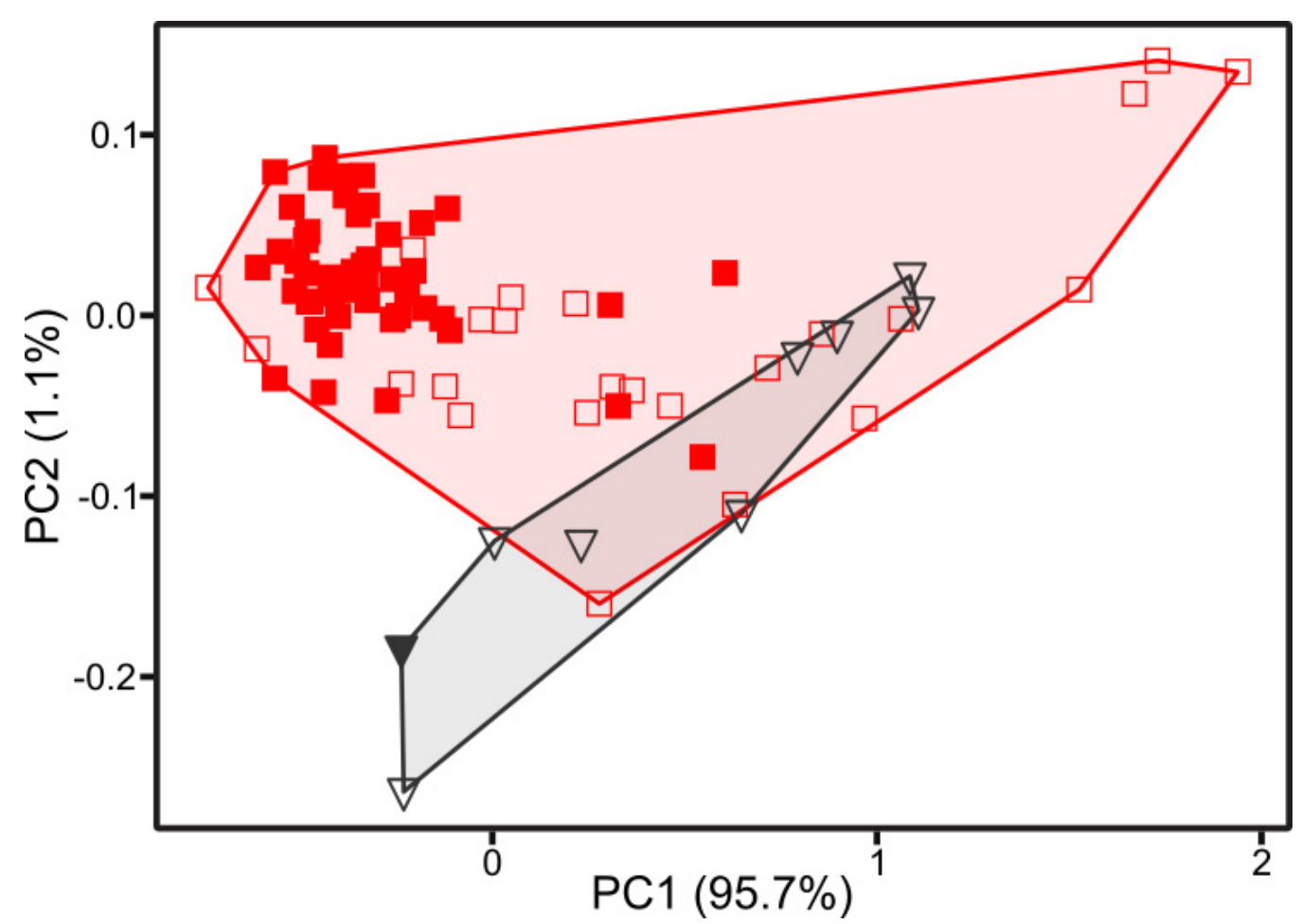

Fig. 6. Scatterplot of $\mathrm{PC} 2$ against $\mathrm{PC} 1$ of the PCA $(\mathrm{n}=83)$ on 24 log-transformed measurements. For group B, the filled squares ( $\square$ ) represent the specimens used for the genetic analysis, the open squares $(\square)$ indicate the additional specimens of the Lake Edward system and the two specimens from Tshambi. Specimens of E. mimus (Boulenger, 1912) (lectotype) ( $\boldsymbol{\nabla})$ and E. mimus (paralectotypes) $(\nabla)$. 
Here, the most important loadings for PC2 were for the snout length, the pelvic fin length and the interorbital width (Supplementary File SM.07).

In the analysis of measurements restricted to group B, one of the types of E. alberti was situated within the polygon of the types of E. mimus (Fig. 5a). In that of the measurements of group A (Fig. 4a), the same specimen was situated closest to the polygon of the types of E. mimus. This specimen had an aberrant value for the number of lateral line scales (23) compared to the other types of E. alberti (31 and 32), which corresponds more to the number of lateral line scales found in group B (21 to 31 with median 26). Furthermore, the aberrant specimen had 32 vertebrae in total, while the other two types of E. alberti had 35 vertebrae. The total number of vertebrae was 34 to 35 for specimens in group A $(n=4)$ and 31 to 33 in group $B(n=4)$. Based on these results, the aberrant type specimen of E. alberti could be assigned to group $\mathrm{B}$.

\title{
Nomenclature and synonyms
}

\author{
Class Actinopterygii Klein, 1885 \\ Subclass Neopterygii Regan, 1923 \\ Division Teleostei Müller, 1846 \\ Order Cypriniformes Rafinesque, 1810 \\ Family Cyprinidae Rafinesque, 1815
}

Genus Enteromius Cope, 1867

The results confirmed the occurrence of two syntopic species of Enteromius with a smooth dorsal fin ray in the Lake Edward system. Specimens of group A were conspecific with the types of E. alberti, except for one type specimen, which was assigned to group B, and with the holotype and paratypes of E. cercops. Enteromius alberti used to be considered a synonym of E. stigmatopygus. Based on our results, and following the principle of priority for species names, we propose to revalidate $E$. alberti with E. cercops as its junior synonym. A redescription of $E$. alberti is provided based on the lectotype (here designated) (Fig. 7a) and one paralectotype of $E$. alberti, the type series of E. cercops, here synonymised with $E$. alberti, and the additional specimens from the Lake Edward system examined in this study and identified as E. alberti $(\mathrm{n}=37)$. The other paralectotype of E. alberti, which was revealed not to be conspecific with $E$. alberti, was not included in the redescription. The measurements and meristics can be found in Table 2. An illustration of a fresh specimen of E. alberti, captured during the HIPE expeditions is provided in Fig. $7 \mathrm{~b}$.

The specimens of group B were most similar to E. mimus, though the PCA on log-transformed measurements (Fig. 6) suggested some differences. Therefore, we decided to assign the specimens of group B to E. cf. mimus with "cf" indicating specimens that are comparable to E. mimus but whose identification is uncertain (Decru et al. 2016). Because of the unsuitable original description of E. mimus for modern taxonomic purposes, we decided to make a redescription based on the lectotype (here designed) (Fig. 8) and eight of the nine paralectotypes of E. mimus. We found one paralectotype to have a serrated dorsal fin ray; therefore, it was considered not to be conspecific with the other types and excluded from the redescription. Specimens from the Lake Edward system identified as E. cf. mimus, the specimens from Tshambi and the aberrant lectotype of $E$. albert $i$ were not included in the redescription, but their measurements and meristics are given in Table 2. A picture of a fresh specimen of $E$. cf. mimus is given in Fig. 9.

For both redescribed species, a lectotype was chosen from the syntypes. For E. alberti, this is the specimen illustrated in the original description by Poll (1939), which is also the largest specimen. The lectotype of E. mimus is the specimen that resembles most the original figure of E. mimus in the Catalogue of the Fresh-water Fishes of Africa in the British Museum (Natural History), Volume IV, by Boulenger (1916). 
MAETENS H. et al., Species of Enteromius from the Lake Edward system

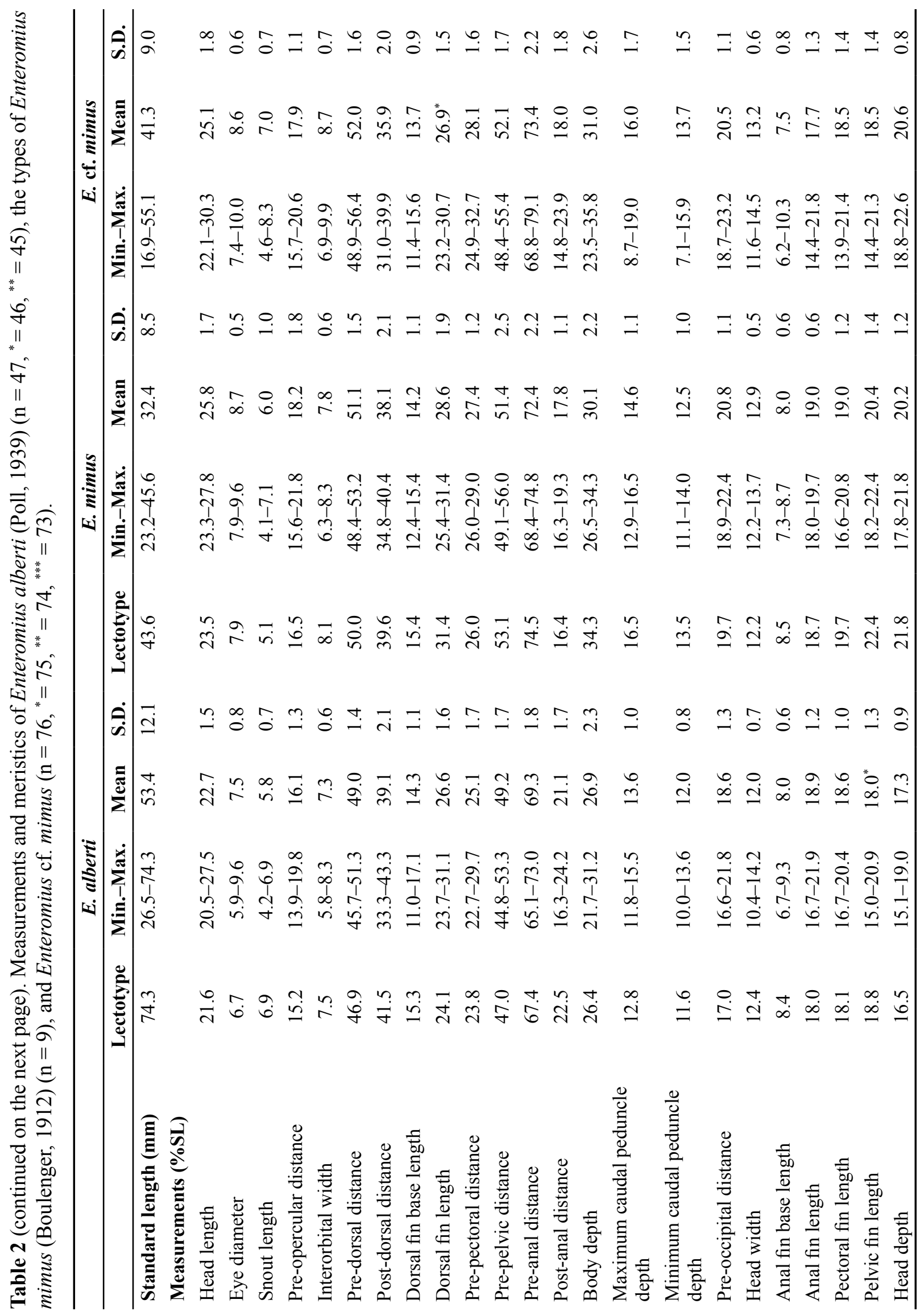




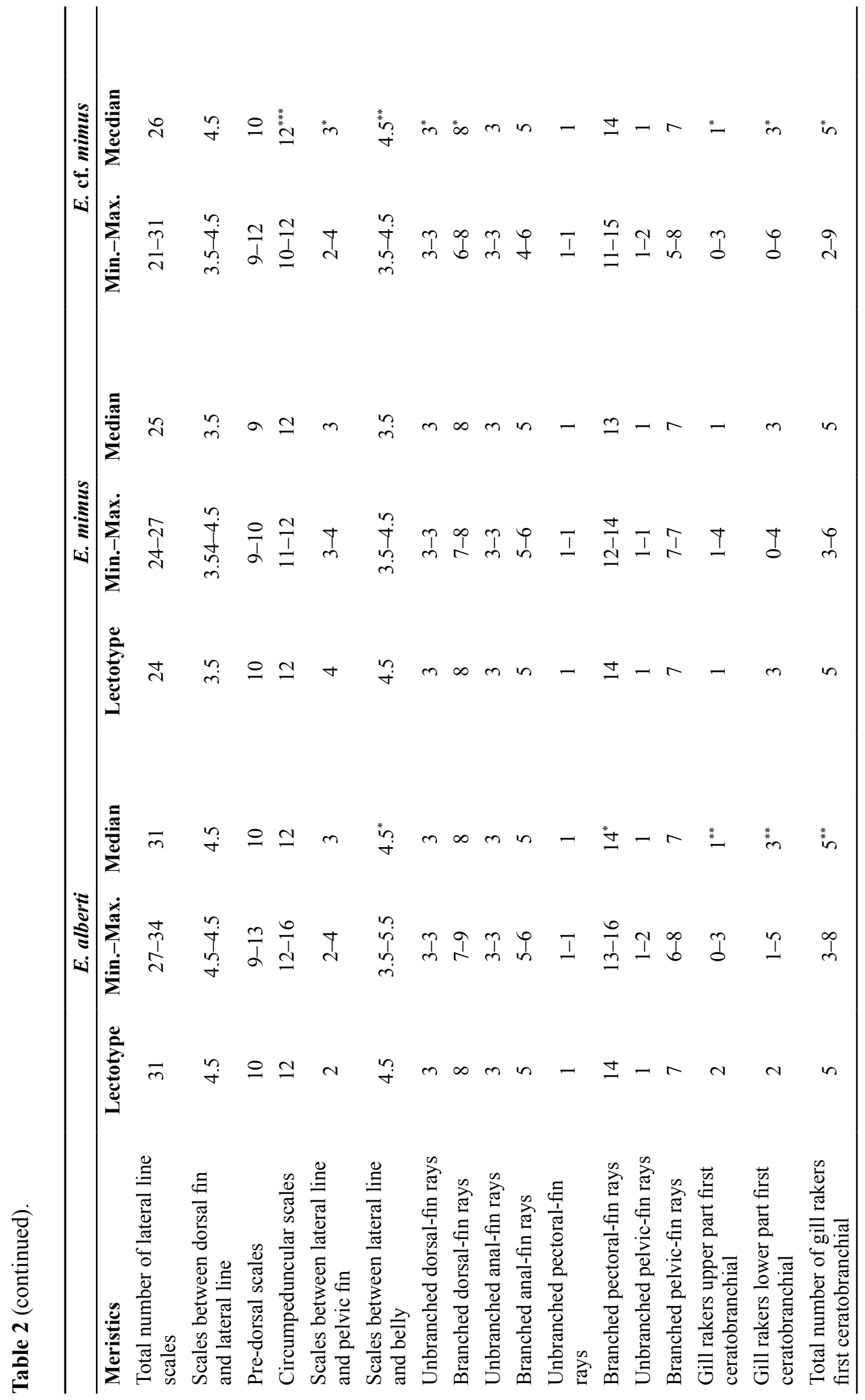


The sampling sites of the two species in the Lake Edward system and the type localities of E. mimus, E. alberti and E. cercops are illustrated in Fig. 10. The specimens from Tshambi, initially identified as $E$. alberti, are indicated as E. cf. mimus on the map, as found in the present study.

Enteromius alberti (Poll, 1939)

Fig. $7 \mathrm{a}-\mathrm{b}$, Table 2

Enteromius cercops (Whitehead, 1960) (here synonymised). syn. nov.

\section{Diagnosis}

Enteromius alberti (Fig. 7a-b) belongs to the group of species of Enteromius with a flexible last unbranched dorsal fin ray that lacks serrations along its posterior edge. A comparison was made with other species of Enteromius from this group from the East Coast and Nilo-Sudan ichthyofaunal provinces (list made based on information available in, e.g., Greenwood 1962; Okaronon et al. 1997; Seegers et al. 2003; Schmidt et al. 2017; Froese \& Pauly 2018). Enteromius alberti can easily be distinguished from the other species of this group from the East Coast and Nilo-Sudan ichthyofaunal regions by the following combination of characteristics (data from original description, unless otherwise stated): a complete lateral line vs an incomplete lateral line in E. atkinsoni (Bailey, 1969), E. pumilus (Boulenger, 1901), E. serengetiensis (Farm, 2000), E. tongaensis (Rendahl, 1935) and E. toppini (Boulenger, 1916); two pairs of barbels vs one pair in E. pseudotoppini (Seegers, 1996), and no barbels in E. anema (Boulenger, 1903) and E. profundus (Greenwood, 1970); one to three dark spots on the flanks, which
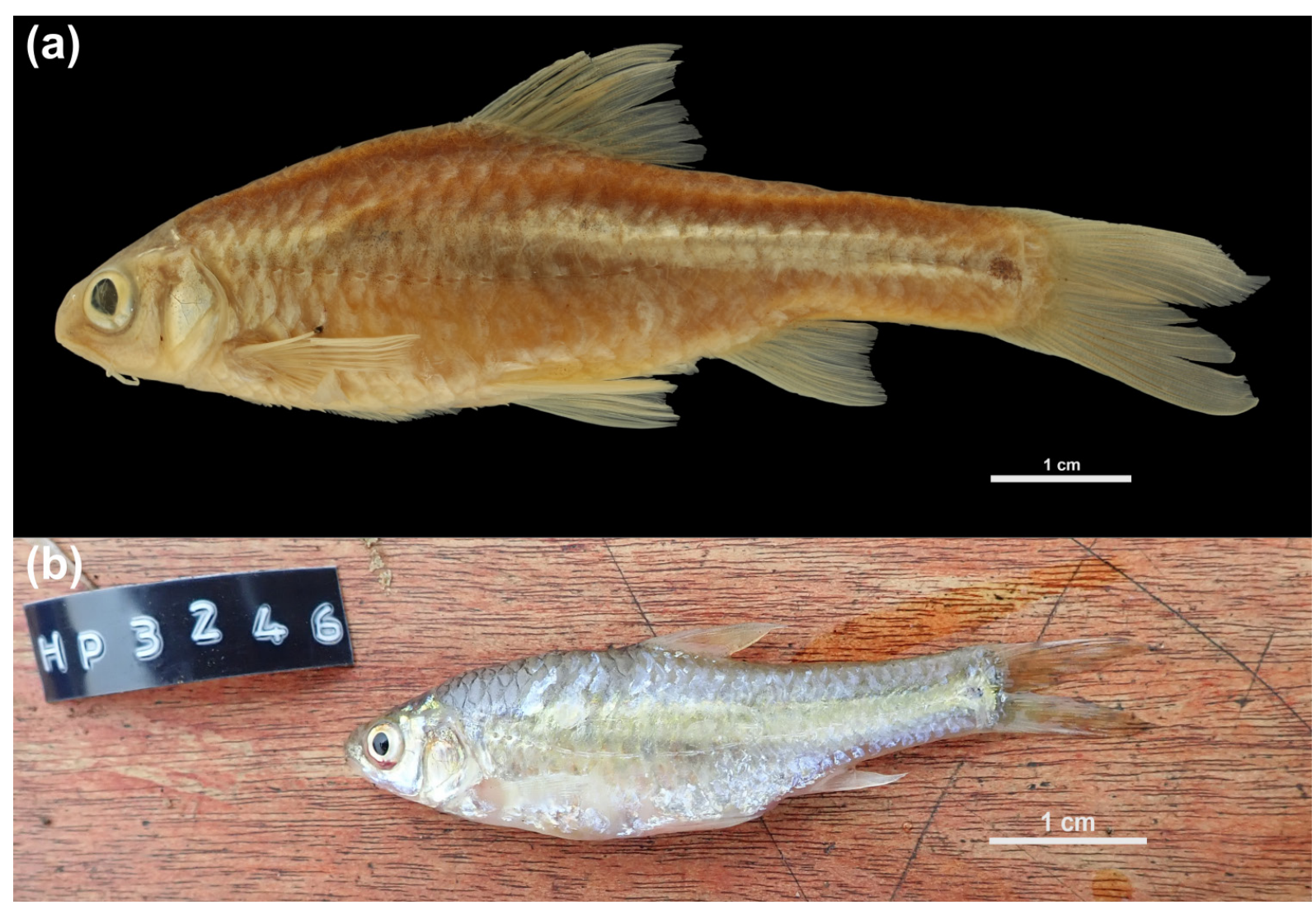

Fig. 7. (a) Lectotype of Enteromius alberti (Poll, 1939) (MRAC 64723) with $74.3 \mathrm{~mm}$ SL. (b) Fresh specimen of E. alberti (RMCA 2018.008.P.0248 HP 3246) with $62.4 \mathrm{~mm}$ SL. 
sometimes fuse into a mid-lateral line in preserved specimens, starting posterior to the operculum vs a dark line running from the tip of the snout to the caudal fin base in E. bifrenatus (Fowler, 1935) and E. yongei (Whitehead, 1960), and a thin dark line from the beginning of the operculum to the caudal fin base in E. viviparus (Weber, 1897); 12 scales around the caudal peduncle, with one aberrant specimen in the paratypes of E. cercops (16), vs 8 in E. leonensis (Boulenger, 1915), 9-10 in E. venustus (Bailey, 1980), and 10 in E. magdalenae (Boulenger, 1906) and E. yeiensis (Johnsen, 1926); 4.5 scales between the dorsal fin base and the lateral line vs 3.5 in E. radiatus (Peters, 1853) (Greenwood 1970), 5.5 in E. unitaeniatus (Günther, 1867), and 6 in E. usambarae (Lönnberg, 1907); a dorsal fin length which is larger than the head length vs a dorsal fin length equal to the head length in E. innocens (Pfeffer, 1896); a body depth which is larger than the head length vs a body depth which is equal to the head length in E. nigeriensis (Boulenger, 1903) and E. trispilopleura (Boulenger, 1902); a pectoral fin length which is $5 / 6$ of the head length vs $3 / 4$ in E. lineomaculatus (Boulenger, 1903), and $2 / 3$ to $3 / 4$ in E. neglectus (Boulenger, 1903) (Boulenger 1907); a maximum caudal peduncle depth which is $3 / 5$ of the head length vs $2 / 5$ in E. quadripunctatus (Pfeffer, 1896). Enteromius alberti differs from $E$. perince by a combination of a smaller body depth [21.7-31.2\% SL (mean 26.9) vs 33.8-37.5 (35.0)], a smaller minimum caudal peduncle depth [10.0-13.6\% SL (mean 12.0) vs 15.0-16.4 (15.5)], and a smaller maximum caudal peduncle depth [11.8-15.5\% SL (mean 13.6) vs 17.7-19.4 (18.8)]. Enteromius alberti differs from E. stigmatopygus by a combination of a higher number of lateral line scales [27-34 (median 31) vs 20-25 (21)], a smaller pre-dorsal distance [45.7-51.3\% SL (mean 49.0) vs 51.9-55.8 (53.8)] and a smaller pre-occipital distance [16.6-21.8\% SL (mean 18.6) vs 22.1-27.3 (24.0)]. Enteromius alberti differs from E. mimus by a higher number of lateral line scales [27-34 (median 31) vs 24-27 (25)], a smaller pre-anal distance [65.1-73.0\% SL (average 69.3) vs 68.4-74.8 (72.4)], a larger post-anal distance [16.3-24.2\% SL (average 21.1) vs 16.3-19.3 (17.8)], a smaller body depth [21.7-31.2\% SL (average 26.9) vs 26.5-34.3 (30.1)], a smaller head depth [15.1-19.0\% SL (average 17.3) vs 17.8-21.8 (20.2)] and a smaller pelvic fin length [15.0-20.9\% SL (average 18.0) vs 18.2-22.4 (20.4)] (Table 2). Specimens of $E$. alberti differ from the population of $E$. cf. mimus from the Lake Edward system by a smaller head depth. In general, a specimen with a head depth smaller than $19 \%$ of the standard length can be assigned to E. alberti (only one specimen had a higher value). Specimens with a head depth larger than $19 \%$ of the standard length can be assigned to $E$. cf. mimus (only one specimen had a lower value). Other characters to distinguish $E$. alberti from $E$. cf. mimus are the higher number of lateral line scales [27-34 (median 31) vs 21-31 (26)], the smaller interorbital width [5.8-8.3\% SL (mean 7.3) vs 6.9-9.9 (8.7)], the smaller pre-pelvic distance [44.8-53.3\% SL (mean 49,2) vs 48.4-55.4 (52.1)], the smaller body depth [21.7-31.2\% SL (mean 26.9) vs 23.5-35.8 (31.0)], the smaller maximum [11.8$15.5 \%$ SL (mean 13.6) vs 8.7-19.0 (16)] and minimum [10.0-13.6\% SL (mean 12) vs 7.1-15.9 (13.7)] caudal peduncle depth, and the smaller head width [10.4-14.2\% SL (mean 12) vs 11.6-14.5 (13.2)] (Table 2, Fig. 3).

\section{Etymology}

Etymology not explained in the original description. Probably, the species epithet alberti is derived from the name of the former 'Parc National Albert' (now Virunga National Park) in which the type locality is located.

\section{Material examined}

Lectotype (here designated)

DEMOCRATIC REPUBLIC OF THE CONGO • Rutshuru River, May-Ya-Moto; 5-11 Nov. 1934; de Witte leg.; MRAC 64723 (Supplementary file SM.01: Fiche-209).

\section{Paralectotype}

DEMOCRATIC REPUBLIC OF THE CONGO 1 spec.; same collection data as for lectotype; MRAC 64722 (Supplementary file SM.01: Fiche-210). 


\section{Other material examined}

KENYA - Lake Victoria basin - 1 spec., holotype of E. cercops; Luambwa, Nzoia River, Nyanza Province; 1960; BMNH 1960.6.7.37 7 specs [of 13 in lot], paratypes of E. cercops; same collection data as for holotype; BMNH 1960.6.7.38 to 1960.6.7.50 (Supplementary file SM.01: Fiche-177 to Fiche-183).

UGANDA - Lake Edward - 1 spec. [of 2 in lot]; Nchwera River, Rwenshama-Ishasha road; $0^{\circ} 27^{\prime} 30.8^{\prime \prime}$ S, 294ㅇ'07.0" E; 8 Nov. 2016; HIPE exped.; GenBank: MT251114; RMCA 2016.035.P.0148 to 2016.035.P.0149 (Supplementary file SM.01: E31). 1 spec. [of 2 in lot]; same collection data as for preceding; RMCA 2016.035.P.0171 to 2016.035.P.0172 (Supplementary file SM.01: HP1028)• 1 spec.; Kayanja, offshore, Lake Edward; 005'31.2" S, 29²5'30.3" E; 20 Jan. 2018; HIPE exped.; GenBank: MT251133; RMCA 2018.008.P.0247 (Supplementary file SM.01: HP2599). 2 specs.; Nyamweru River, mouth, Kisenji; $0^{\circ} 18^{\prime} 42.5^{\prime \prime} \mathrm{S}, 2^{\circ} 51^{\prime} 36.0^{\prime \prime}$ E; 31 Jan. 2018; HIPE exped.; RBINS 25585 to 25586 (Supplementary file SM.01: Fiche-118, Fiche-119) - Lake George • 5 specs; River $2 \mathrm{~km}$ east of Kitongore; $0^{\circ} 05^{\prime} 45.6^{\prime \prime} \mathrm{S}, 30^{\circ} 40^{\prime} 51.6^{\prime \prime} \mathrm{E}$; 31 Oct. 2016; HIPE exped.; GenBank: MT251105, MT251120, MT251121, MT251106, MT251107; RMCA 2016.035.P.0159 to 2016.035.P.0163 (Supplementary file SM.01: HP592, HP595, HP596, HP600, HP602) - 2 specs; Mpanga River, mouth, Lake George; $0^{\circ} 02^{\prime} 20.4^{\prime \prime}$ N, 30¹7'24.0" E; 31 Oct. 2016; HIPE exped.; GenBank: MT251119, MT251104; RMCA 2016.035.P.0164 to 2016.035.P.0165 (Supplementary file SM.01: HP575, HP579) • 1 spec.; Mahoma River, Rwimi-Nyabani road; $0^{\circ} 21^{\prime} 00.2^{\prime \prime}$ N, 30¹6'41.0" E; 1 Apr. 2017; HIPE exped.; GenBank: MT251110; RMCA 2017.006.P.0244 (Supplementary file SM.01: HP1878) • 1 spec.; Lake George, Kashaka Bay, south of inlet; 0 05'04.6" S, 30¹0'45.6" E; 2 Feb. 2018; HIPE exped.; GenBank: MT251111; RMCA 2018.008.P.0248 (Supplementary file SM.01: HP3246) - Kazinga Channel - 4 specs; Kyambura River, mouth, Kazinga Channel; 007'25.8" S, 3003'07.5" E; 30 Oct. 2016; HIPE exped.; GenBank: MT251100, MT251101, MT251102, MT251103; RMCA 2016.035.P.0155 to 2016.035.P.0158 (Supplementary file SM.01: HP562(2), HP563 to HP565) - 7 specs; same locality; 4 Feb. 2018; HIPE exped.; RBINS 25588 to 25594 (Supplementary file SM.01: Fiche-143 to Fiche-149) - 4 specs; same collection data as for preceding; GenBank: MT251099, MT251112; RMCA 2018.008.P.0249 to 2018.008.P.0252 (Supplementary file SM.01: HP3312, HP3314, HP3317, HP3319) • 1 spec.; Kyambura River, middle course, north of Lake Katinda; $0^{\circ} 12^{\prime 2} 23.7^{\prime \prime}$ S, 30 $00^{\circ} 24.3^{\prime \prime}$ E; 2 Feb. 2018; HIPE exped.; RBINS 25587 (Supplementary file SM.01: Fiche-128) 5 specs; Kazinga Channel, near Queen Elisabeth Bush Lodge; 008'09.6" S, 3002'27.6" E; 4 Nov. 2016; HIPE exped.; GenBank: MT251123, MT251124, MT251125, MT251108, MT251109; RMCA 2016.035.P.0166 to 2016.035.P.0170 (Supplementary file SM.01: HP719 to HP721, HP723, HP724) - 2 specs; Kazinga Channel, opposite of mouth Kyambura River; $0^{\circ} 07^{\prime} 17.5^{\prime \prime}$ S, 30 $02^{\prime} 59.0^{\prime \prime}$ E; 4 Feb. 2018; HIPE exped.; RBINS 25595 to 25596 (Supplementary file SM.01: Fiche-121, Fiche-123).

\section{Description}

Based on the lectotype and one paralectotype of E. alberti, the type series of E. cercops, which is synonymised here as E. alberti, and 37 additional specimens from the Lake Edward system, identified as E. alberti. The lectotype is illustrated in Fig. 7a. Maximum observed size: $74.3 \mathrm{~mm}$ SL. Morphometric and meristic data are given in Table 2. Body fusiform, largest depth anterior to dorsal fin. Dorsal profile from tip of snout to origin of dorsal fin slightly convex, slightly tapering to base of caudal fin. Ventral profile from operculum to origin of pelvic fin slightly convex, slightly tapering to posterior end of anal fin base, then slightly concave to caudal fin. Head small. Eye large and round, located dorso-laterally, closer to tip of snout than to distal margin of operculum, interorbital profile slightly convex. Snout rounded and mouth subterminal. Two pairs of barbels, anterior barbel usually slightly shorter than posterior with anterior one usually reaching up to vertical through posterior margin of eye, while posterior one usually up to vertical trough posterior margin of pre-operculum. Dorsal fin with 3 unbranched and 7 to 9 branched rays, distal margin straight to slightly concave, origin located slightly anterior [1 or 2 lateral 
line scale(s)] to vertical through pelvic fin insertion. First branched dorsal fin ray longest, posterior rays decreasing progressively in size. Pectoral fin with 1 unbranched and 13 to 16 branched rays, distal profile straight to slightly convex, not reaching anterior base of pelvic fin. Pelvic fin with 1 unbranched and 6 to 8 branched rays, distal margin slightly convex. Anal fin with 3 unbranched and 5 to 6 branched fin rays, distal margin slightly concave. Caudal fin forked with outer rays twice as long as median ones and both lobes rounded and of similar size. Anus and urogenital opening situated immediately in front of anal fin base. Scales cycloid, rounded and radially striate. Lateral line completely pored with many lateral line scales [27-34 (median 31)], and gently curved downwards over abdomen but running straight along middle of caudal peduncle and ending at base of caudal fin. Lateral-line scales smaller on caudal peduncle than below dorsal fin.

\section{Colour pattern}

No sexual dimorphism observed. In life, overall background colour of body silvery, darker toward dorsum and lighter towards belly (Fig. 7b). Thick yellowish midlateral band, often with one to three darker spots. All fins translucent. In preserved specimens, overall background colour of body yellowish, greyish dorsally (Fig. 7a). One to three dark spots on flanks on thick silvery midlateral band; spots fused into mid-lateral line in some specimens, overlying silvery band and starting posterior to operculum. First spot situated anterior to dorsal fin origin, median one below last ray of dorsal fin and last one at caudal fin base. Specimens with more than three spots are rare $(1$ specimen with 4 spots and another with 6 spots).

\section{Distribution (Fig. 10)}

Enteromius alberti occurs in river systems throughout the Lake Edward basin. For the Congolese part of the basin, it is known from its type locality, the Rutshuru River, May-Ya-Moto (Poll 1939). Although the Congolese part of the system was not sampled during the recent expeditions, we identified specimens from the collection at the RMCA (86-01-P-479 to 500 and 86-09-P-70 to 71) from Vitshumbi, located in the southern Congolese part of the Lake Edward system, as E. alberti. In the Ugandan part, we collected the species in the Mahoma, Mpanga, Nchwera, Nyamweru and Kyambura (an affluent of the Rusangwe) Rivers, in Lake Edward offshore at Kayanja, and in Lake George at Kashaka Bay. For the Lake Victoria basin, E. alberti is known from the Nzoia River, the Malawa River and the Middle Akagera system (Whitehead 1960; Greenwood 1966; De Vos \& Thys van den Audenaerde 1990; Seegers et al. 2003).

\section{Enteromius mimus (Boulenger, 1912)}

Fig. 8, Table 2

\section{Diagnosis}

Enteromius mimus (Fig. 8) belongs to the group of species of Enteromius with a flexible last unbranched dorsal fin ray that lacks serrations along its posterior edge. A comparison was made to other species of Enteromius from this group from the East Coast and Nilo-Sudan ichthyofaunal provinces (list made based on information available in, e.g., Greenwood 1962; Okaronon et al. 1997; Seegers et al. 2003; Schmidt et al. 2017; Froese \& Pauly 2018). Enteromius mimus can easily be distinguished from the other species of this group from the East Coast and Nilo-Sudan ichthyofaunal regions by the following combinations of characteristics (data from original description, unless otherwise stated): a complete lateral line vs an incomplete lateral line in E. atkinsoni, E. pumilus, E. serengetiensis, E. tongaensis and E. toppini; two pairs of barbels vs one pair in E. pseudotoppini, and no barbels in E. anema and E. profundus; one to three dark spots on the flanks, which sometimes fuse into a mid-lateral line in preserved specimens, starting posterior to the operculum vs a dark line running from the tip of the snout to the caudal fin base in E. bifrenatus and E. yongei, and a thin dark line from the beginning of the operculum to the caudal fin base in E. viviparus; $11-12$ scales around the caudal peduncle vs 
8 in E. leonensis, 9-10 in E. venustus, and 10 in E. magdalenae and E. yeiensis; 24-27 lateral line scales (median 25) vs 30 in E. lineomaculatus, and 31 E. innocens; $3.5-4.5$ scales between the dorsal fin base and the lateral line vs 5.5 in E. unitaeniatus, and 6 in E. usambarae; 3-4 scales between the lateral line and the pelvic fin (median 3) vs 2 in E. trispilopleura, and 2-2.5 in E. neglectus (Boulenger 1907); 7-8 branched dorsal fin rays vs 9 in E. quadripunctatus; a body depth which is larger than the head length vs a body depth which is equal to the head length in E. nigeriensis; a smaller snout length [4.1-7.1\% SL (average 6.0) vs 7.1-10.1] in E. radiatus (Greenwood 1970). Enteromius mimus differs from E. perince by a combination of a lower number of lateral line scales [24-27 (median 25) vs 29-30 (30)], a lower number of scales between the dorsal fin base and lateral line [3.5-4.5 (median 3.5) vs 5.5], a lower number of scales around the caudal peduncle [11-12 (median 12) vs 14], a smaller interorbital width [6.3-8.3\% SL (average 7.8) vs 9.8-10.2 (10.0)], a larger pre-pectoral distance [26.0-29.0\% SL (average 27.4) vs 23.1-24.5 (23.8)], a lower minimum caudal peduncle depth [11.1-14.0\% SL (average 12.5) vs 15.0-16.4 (15.5)], a lower maximum caudal peduncle depth [12.9-16.5\% SL (average 14.6) vs 17.7-19.4 (18.8)], and a smaller anal fin base length [7.3-8.7\% SL (average 8.0) vs 8.5-9.6 (9.1)]. Enteromius mimus differs from E. stigmatopygus by a combination of a smaller pre-pectoral distance [26.0-29.0 (average 27.4) vs 29.1-33.1 (30.8)], and a larger anal fin length [18.0-19.7 (average 19.0) vs 12.6-17.4 (14.8)]. Enteromius mimus differs from E. alberti by a lower number of lateral line scales [24-27 (median 25) vs 27-34 (31)], a larger pre-anal distance [68.4-74.8\% SL (average 72.4) vs 65.1$73.0(69.3)$ ], a smaller post-anal distance [16.3-19.3\% SL (average 17.8) vs 16.3-24.2 (21.1)], a larger body depth [26.5-34.3\% SL (average 30.1) vs 21.7-31.2 (26.9)], a larger head depth [17.8-21.8\% SL (average 20.2) vs 15.1-19.0 (17.3)] and a larger pelvic fin length [18.2-22.4\% SL (average 20.4) vs 15.0-20.9 (18.0)] (Table 2). Specimens from E. mimus differ from the specimens of the population of E. cf. mimus from the Lake Edward system by a lower number of scales between the origin of the dorsal fin and the lateral line [3.5-4.5 (median 3.5) vs 3.5-4.5 (4.5)], a larger pelvic fin length [18.2-22.4\% SL (average 20.4) vs 14.4-21.3 (18.5)], a smaller snout length [4.1-7.1\% SL (average 6.0) vs 4.6-8.3 (7.0)], a smaller interorbital width [6.3-8.3\% SL (average 7.8) vs 6.9-9.9 (8.7)], a larger post-dorsal distance [34.8-40.4\% SL (average 38.1) vs 31.0-39.9 (35.9)] and a larger anal fin length [18.0-19.7\% SL (average 19.0) vs 14.4-21.8 (17.7)] (Table 2).

\section{Etymology}

The specific epithet 'mimus' means 'imitator', a reference to the 'striking resemblance' to E. neglectus (Boulenger 1912; Scharpf \& Lazara 2019).

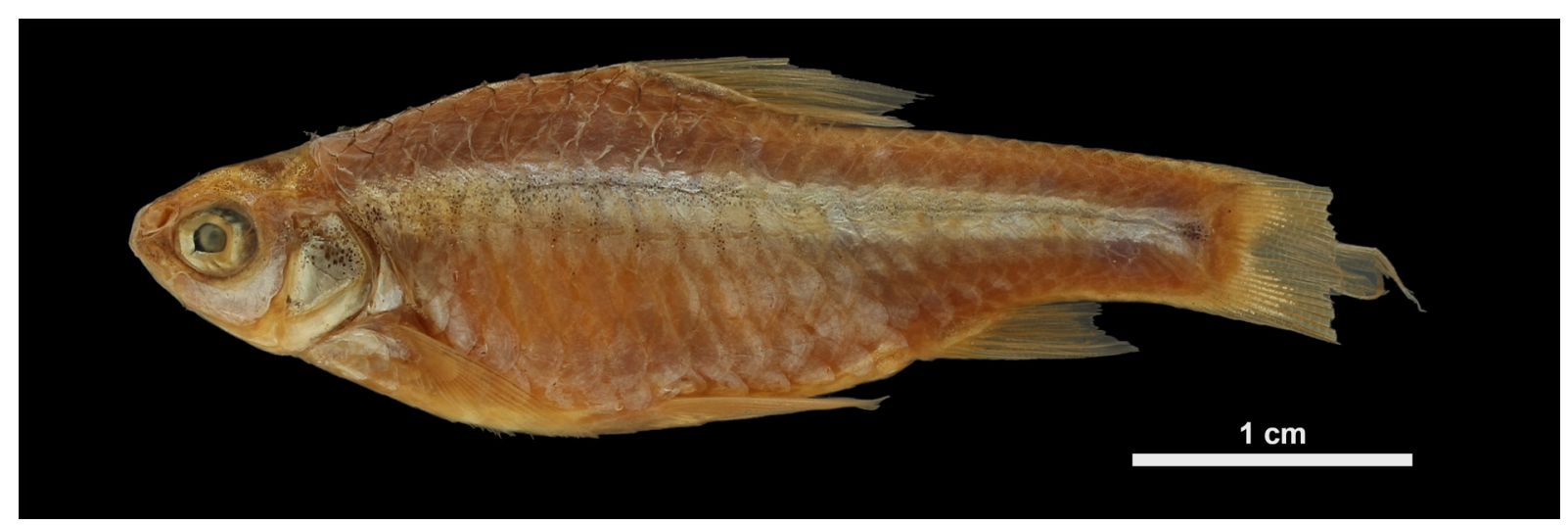

Fig. 8. Lectotype of Enteromius mimus (Boulenger, 1912) (BMNH 1912.3.22.99) with 43.6 mm SL. 


\section{Material examined}

Lectotype (here designated)

KENYA •Euasso Nyiro, bellow falls, British EastAfrica; BMNH 1912.3.22.99(Supplementary file SM.01: Fiche-185).

\section{Paralectotypes}

KENYA • 8 specs [of 9 in lot]; same collection data as for lectotype; BMNH 1912.3.22.90 to 1912.3.22.98 (Supplementary file SM.01: Fiche-184, Fiche-186 to Fiche-188, Fiche-B to Fiche-E).

\section{Description}

The redescription of E. mimus is based on the specimens of the type series only (the lectotype and eight paralectotypes). The lectotype is illustrated in Fig. 8. Maximum observed size: $45.6 \mathrm{~mm}$ SL. Morphometric and meristic data are given in Table 2. Body fusiform, largest depth anterior to dorsal fin. Dorsal profile from tip of snout to origin of dorsal fin slightly convex, slightly tapering to base of caudal fin. Ventral profile from operculum to origin of pelvic fin slightly convex, slightly tapering to posterior end of anal fin base, then slightly concave to caudal fin. Head small. Eye large and round, located laterally, closer to tip of snout than distal margin of operculum, interorbital profile slightly convex. Snout rounded. Mouth subterminal. Two pairs of barbels, anterior barbel shorter than posterior with anterior one usually reaching up to vertical through the middle of the eye, while posterior one can reach the vertical trough posterior margin of pre-operculum. Dorsal fin with 3 unbranched and 7 to 8 branched rays, distal margin slightly concave, origin located on vertical through pelvic fin insertion or slightly anterior (1 lateral line scale). First branched dorsal fin ray longest, posterior rays decreasing progressively in size. Pectoral fin with 1 unbranched and 12 to 14 branched rays, distal profile straight to slightly convex, not reaching anterior base of pelvic fin. Pelvic fin with 1 unbranched and 7 branched rays, distal margin convex. Anal fin with 3 unbranched and 5 to 6 branched fin rays, distal margin concave. Caudal fin forked with outer rays twice as long as median ones and both lobes rounded and of similar size. Anus and urogenital opening situated immediately in front of anal fin base. Scales cycloid rounded and radially striate. Lateral line completely pored with many lateral line scales (total) [24-27 (median 25)], gently curved downwards over abdomen but running straight along middle of caudal peduncle and ending at base of caudal fin.

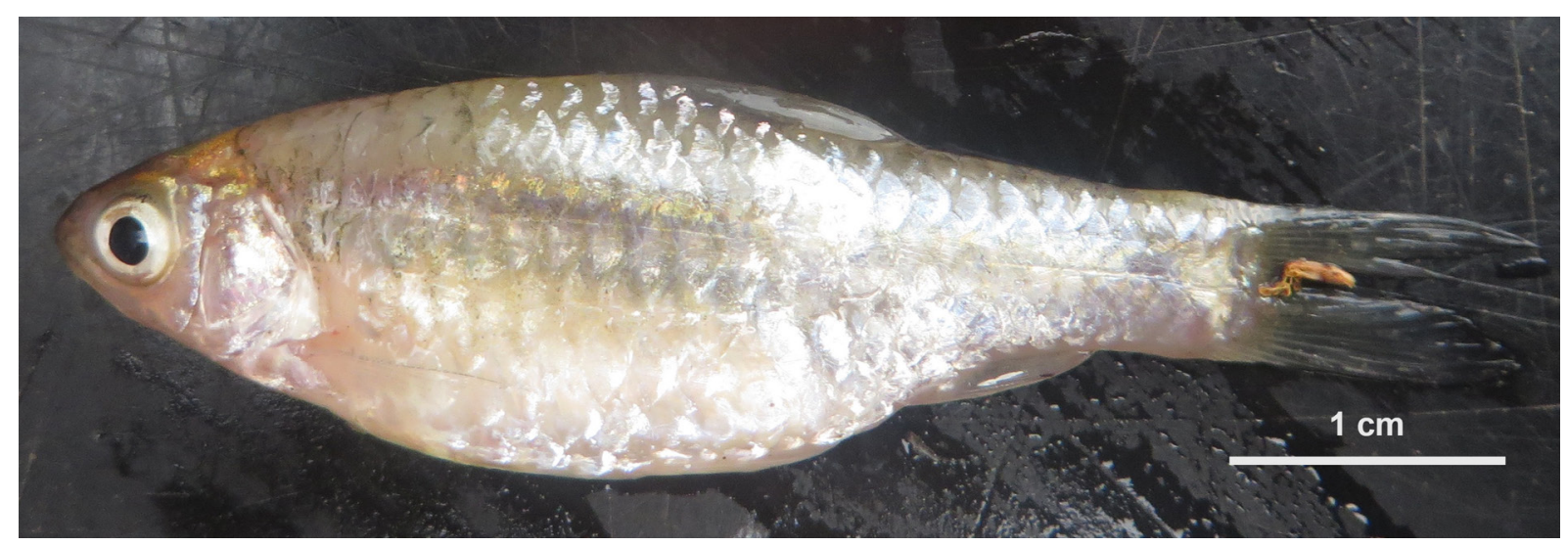

Fig. 9. Fresh specimen of $E$. cf. mimus (Boulenger, 1912) (RMCA 2016.035.P.0125-0139 HP547) with $45.2 \mathrm{~mm}$ SL. 


\section{Colour pattern}

No sexual dimorphism is observed. No information of in vivo colour pattern is available. In preserved specimens, overall background colour of body brown, darker dorsally. One to three dark spots on flanks on thick silvery midlateral band; spots fused into mid-lateral line in some specimens, overlying silvery band and starting posterior to operculum. First spot situated anterior to dorsal fin origin, median one below or somewhat anterior to last ray of dorsal fin and last one at caudal fin base.

\section{Distribution}

Enteromius mimus is known from its type locality, the Euasso Nyiro River below the falls, east of Lake Baringo, Kenya, and from the Tana River system (Seegers et al. 2003). For the time being, the specimens of the Lake Edward system are referred to as E. cf. mimus and are not included in the distribution of E. mimus.

\section{Discussion}

\section{Enteromius alberti and Enteromius cf. mimus}

Although the occurrence of E. perince and E. stigmatopygus in the Lake Edward system was mentioned in several studies (e.g., Poll 1939; Greenwood 1966; Decru et al. 2019), we found that the specimens from the Lake Edward system, previously assigned to these species, clearly differed from the syntypes of these species in morphology. The genetic distance between the specimens from the Lake Edward system and sequences of $E$. perince from GenBank was large (12\%). Based on our study, we can conclude that E. perince and E. stigmatopygus do not occur in the system. Instead, the specimens of Enteromius from the Lake Edward system with a smooth unbranched dorsal fin ray are assigned to either E. alberti ("group A") or E. cf. mimus ("group B"), which share a very similar colour pattern. However, no correspondence was found between specimens previously identified as E. stigmatopygus or E. perince and their current identification as E. alberti or E. cf. mimus. Specimens from the system, which were historically assigned to $E$. stigmatopygus, include both specimens of $E$. alberti and $E$. cf. mimus. The same applies to specimens historically assigned to $E$. perince.

Banister (1987) considered E. alberti to be a synonym of E. stigmatopygus, although he did not examine the syntypes of $E$. alberti. The synonymy was based on a similar position of the gill rakers, the alignment of pharyngeal tooth rows and the position of the flank spots. However, the number of lateral line scales was different (Banister, 1987); 24 to 26 in E. stigmatopygus, according to Banister (1987), compared to 31 in E. alberti, according to Poll (1939). We found similar differences in the present study: E. alberti has 27 to 34 and the type series of E. stigmatopygus has 20 to 25 lateral line scales. Furthermore, in the original description of E. stigmatopygus, Boulenger (1903) mentioned that the syntypes had no barbels. However, Banister (1987) found one pair of posterior barbels in the three largest syntypes, and no sign of anterior barbels, but at the same time emphasized the poor condition of these syntypes. Also in the present study, we did not find distinct anterior barbels. Posterior barbels were found in the larger type specimens of E. stigmatopygus. In his redescription, Banister (1987) included additional specimens (amongst which the types of $E$. alberti) and stated that the anterior barbels appear later in development. The two pairs of barbels in E. alberti are clearly visible.

In the present study, we found the holotype and the examined paratypes of E. cercops to be conspecific with E. alberti. Enteromius cercops was described in 1960 from the Nzoia River (Nyanza Province, Kenya, Lake Victoria basin) by Whitehead. In addition to its type locality, E. cercops is also known from other rivers in the Lake Victoria basin, such as the Malawa River (Uganda) and rivers in the Middle Akagera system (Rwanda) (Whitehead 1960; Greenwood 1966; De Vos \& Thys van den Audenaerde 1990; Seegers et al. 2003). We revalidated E. alberti with E. cercops as its junior synonym. 
We found the specimens of "group B" to be most similar to E. mimus. The syntypes of E. mimus originated from the Euasso Nyiro River (Kenya), which drains to the Indian Ocean and is situated further east in the East Coast ichthyofaunal province (Fig. 10). Furthermore, E. mimus is only known from this type locality and from the Tana River system (Seegers et al. 2003). The type series of E. mimus is polyspecific as it included a specimen with serrations on the third unbranched dorsal fin ray (not included in the analyses), though Boulenger (1912) clearly mentioned the lack of serrations as a feature of the species. Further comparative research on the species of Enteromius from the coastal river systems in Kenya is required in order to identify this specimen. Since some small differences were observed between "group B" and E. mimus in the results of the PCA on the measurements (Fig. 6, Table 2), we assigned "group B" to E. cf. mimus, with "cf." indicating specimens that are comparable to E. mimus but whose identification is uncertain (Decru et al. 2016). Furthermore, "group B" and E. mimus occur in distant river systems. Therefore, it is unlikely that the specimens of the Lake Edward system are conspecific with the geographical distant species E. mimus, though this possibility

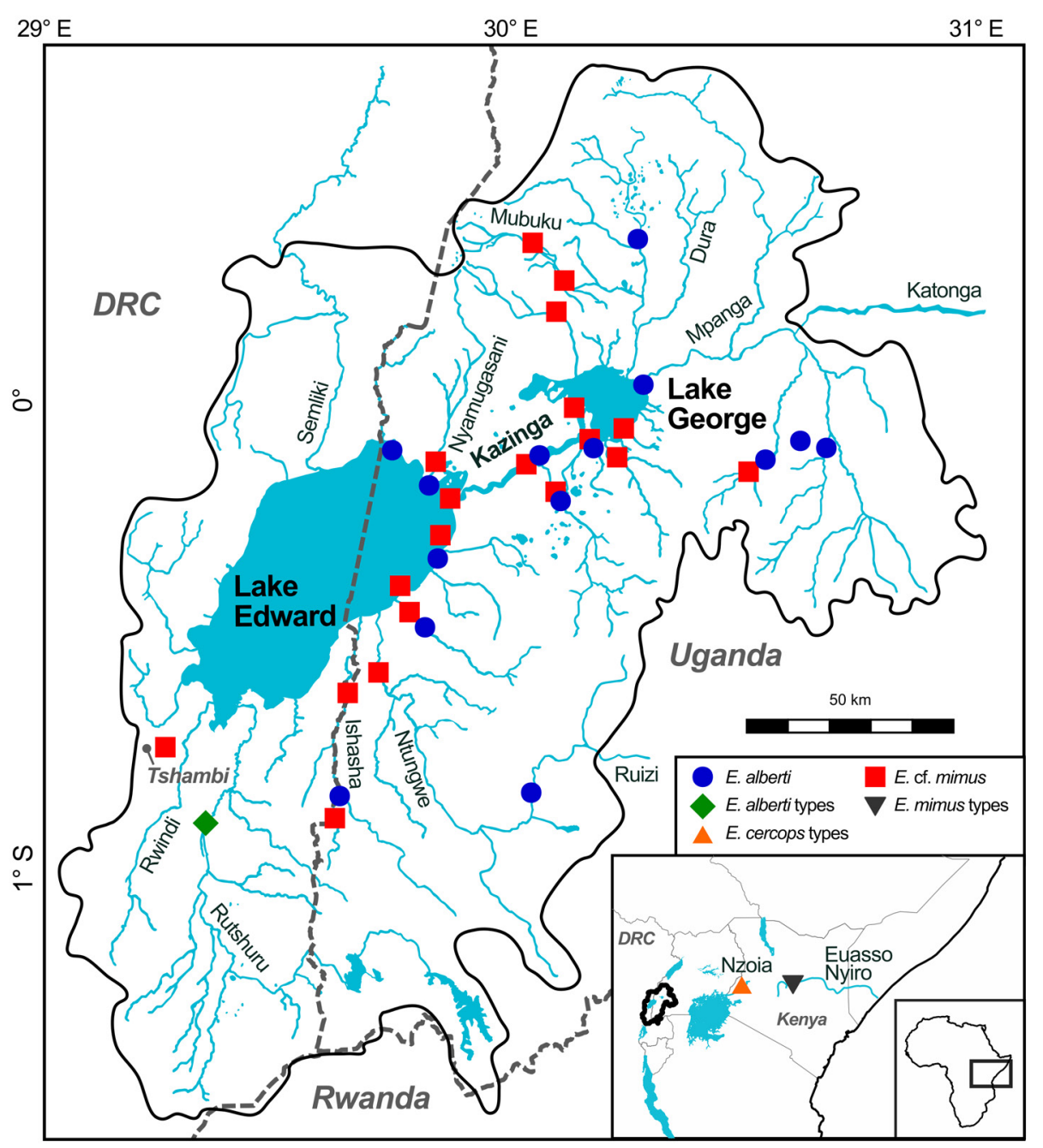

Fig. 10. Overview of the sample locations of E. alberti (Poll. 1939) (•) and E. cf. mimus (Boulenger, 1912) ( $\square$ ), including the specimens from Tshambi, in the Lake Edward system. The location of the lectotype and the paralectotypes of E. alberti ( $\diamond)$. The approximate location of the lectotype and the paralectotypes of E. mimus (Boulenger, 1912) ( $\boldsymbol{\nabla})$ and the holotype and paratypes of E. cercops (Whitehead, 1960) ( $\triangle$ ) are indicated in the inset. 
cannot be excluded. Genetic studies already revealed that widespread species of Enteromius often consist of multiple species that are actually confined to smaller distribution areas (Schmidt et al. 2017; Van Ginneken et al. 2017). While we found E. perince and E. stigmatopygus not to occur in the Lake Edward system, it is remarkable that we found a comparable set of similarly looking species in this system: E. alberti and E. cf. mimus, which mirror E. perince and E. stigmatopygus in the Nile River. Whether or not this implies sister-group relationships between species of Enteromius of the two ichthyofaunal provinces, is difficult to say without a more comprehensive genetic study. Furthermore, $\mathrm{COI}$ data of E. stigmatopygus is lacking. The occurrence of sister relationships between other species of Enteromius from the East Coast and other ichthyofaunal provinces has been suggested by Ndeda et al. (2018). These authors found sister relationship between E. yongei (from Lake Victoria, East Coast) and a lineage containing a specimen identified as $E$. sp. (region of Conakry) and one as E. stigmatopygus (Mafou River, Niger River) with a $12 \%$ genetic divergence in the cytochrome $b$ (Cytb) gene (mtDNA). However, in view of the small sample size, especially of the West African lineage, the vast geographical distance and the use of only one mitochondrial marker, these results need further confirmation.

\section{Unknown diversity in Enteromius}

In a recent study on species of Enteromius from the north-eastern part of the Congo basin (Van Ginneken et al. 2017), DNA barcodes (COI) indicated the presence of 23 mitochondrial lineages within what initially were assumed to be only four different morphospecies. Genetic distances were mostly well over $5 \%$ and even up to $20 \%$ between lineages of morphologically similar specimens, clearly exceeding $2 \%$ which is the cut-off value that is commonly used to denote intraspecific variation (Hebert et al. 2003). In the study of Van Ginneken et al. (2017), clear-cut diagnostic characteristics could, however, not be delineated. Yet, morphologic differences could be demonstrated with multivariate morphometric analyses, which were consistent with the COI lineages. This unrecognised diversity was explained by the occurrence of a cryptic diversity within the species from the Congo basin. In the present study, we found seven characteristics to distinguish the two morphologically similar species of the Lake Edward system. Hence, although, a priori, we failed to distinguish the two species from each other, the concept of cryptic species is not applicable here. Another study (Schmidt et al. 2019) also revealed unrecognised diversity in E. foutensis from the Fouta Djallon (Upper Guinea region) highlands, both genetically (Cytb) and morphologically. Schmidt et al. (2017) also found evidence of high levels of genetic divergence and unrecognized diversity (Cytb) in specimens identified as E. kerstenii, E. apleurogramma and E. cf. paludinosus from the East Coast ichthyofaunal province in Kenya. Also, patterns of introgression seem to occur in both closely and distantly related species of Enteromius (Schmidt et al. 2017), which suggest hybridisation events. Whether this is also the case in the specimens of E. alberti and E. cf. mimus remains to be studied.

The results of these recent integrative studies on other systems raised the expectation to find more species in the Lake Edward system as well. This was, however, not the case for the group with an unbranched third dorsal fin ray. Initially, two species, though misidentified, were reported for this group, and during the present study no additional species were found.

The unrecognised diversity found within species complexes in various systems (e.g., Schmidt et al. 2017, 2019; Van Ginneken et al. 2017), the revalidation of species as found in our study and the study of Schmidt et al. (2018), and the description of new species, such as E. pinnimaculatus from Gabon (Mipounga et al. 2019) and E. thespesios from the Upper Congo River (Katemo Manda et al. 2019) all suggest that the species richness of Enteromius is much larger than currently thought. Hence, the present number of 211 valid species of Enteromius (Froese \& Pauly 2019), is certainly a considerable underestimation of the real species diversity. 


\section{Acknowledgements}

This study is part of the Brain-project HIPE (Human impacts on ecosystem health and resources of Lake Edward), funded by the Belgian Science Policy Office (BELSPO: BR/154/A1/HIPE). The fieldwork has been financed by travel grants from the Fund for Scientific Research (FWO, Belgium). We would like to thank N. Vranken (KU Leuven), M. Mbalassa (Université officielle de Bukavu, DR Congo), L. Wasswa (Ugandan Fisheries Department) and M. Bifamengo (NaFFIRI, Uganda) for their help during the fieldwork as well as W. Okello (NaFFIRI) for the local logistic support during the field trips. We thank J. Maclaine (BMNH) for the loan of specimens under his care. We are also grateful to N. Vranken (KU Leuven) for his help with illustrating the distribution map, to M. Parrent (RMCA) for the registration of the specimens and to A. Mertens (Swedish University of Agricultural Sciences, KU Leuven), A. Kayenbergh (KU Leuven) and K. Dierickx (University of York, KU Leuven) for their help in barcoding the DNA sequences. We thank Dr F. Salah Ali (National Institute of Oceanography and Fisheries, Cairo, Egypt) for giving us more information about the GenBank sequences of E. perince used in this study.

\section{References}

Bamba M. 2012. The 'Barbus' species (Cypriniformes, Cyprinidae) from Côte d'Ivoire: A systematic revision of some West African species complexes. PhD Tesis, KU Leuven, Belgium.

Bamba M., Vreven E.J. \& Snoeks J. 2011. Description of Barbus teugelsi sp. nov. (Cypriniformes: Cyprinidae) from the Little Scarcies basin in Guinea, Africa. Zootaxa 2998: 48-65.

https://org/10.11646/zootaxa.2998.1.4

Banister K.E. 1987. The Barbus perince-Barbus neglectus problem and a review of certain Nilotic small Barbus species (Teleostei, Cypriniformes, Cyprinidae). Bulletin of the Natural History Museum, Zoology series 53 (2): 115-138.

Berrebi P., Kottelat M., Skelton P. \& Rab P. 1996. Systematics of Barbus: state of the art and heuristic comments. Folia Zoologica 45: 5-12.

Bookstein F., Chernoff B., Elder R., Humphries J., Smith G. \& Strauss R. 1985. Morphometrics in Evolutionary Biology: the geometry of size and shape change, with examples from fishes. Journal of the Academy of Natural Sciences of Philadelphia, Special publication 15: 1-277.

Boulenger G.A. 1903. Diagnosis of four new species of Barbus from the Nile. Annals and Magazine of Natural History, Series 7 12: 532-533. https://doi.org/10.1080/00222930308678890

Boulenger G.A. 1907. Zoology of Egypt: the Fishes of the Nile. Published for the Egyptian Government by Hugh Rees, London. https://doi.org/10.5962/bhl.title.51710

Boulenger G.A. 1912. On a collection of Fishes made by Mr. A. Blayney Percival in British East Africa to the East of Lake Baringo. Proceedings of the Zoological Society of London 82 (3): 672-676. https://doi.org/10.1111/j.1469-7998.1912.tb07548.x

Boulenger G.A. 1916. Catalogue of the Fresh-Water Fishes of Africa in the British museum (Natural History), Vol. IV. British Museum (Natural History), London, UK. https://doi.org/10.5962/bhl.title.8869

Clark K., Karsch-Mizrachi I., Lipman D.J., Ostell J. \& Sayers E.W. 2016. GenBank. Nucleic Acids Research 44 (D1): D67-D72. https://doi.org/10.1093/nar/gkv1276

De Vos L. \& Thys van den Audenaerde D.F.E. 1990. Petit Barbus (Pisces, Cyprinidae) du Rwanda. Revue d'Hydrobiologie tropicale 23 (2): 141-159. 
Decru E., Vreven E. \& Snoeks J. 2012. A revision of the West African Hepsetus (Characiformes: Hepsetidae) with a description of Hepsetus akawo sp. nov. and a redescription of Hepsetus odoe (Bloch, 1794). Journal of Natural History 46: 1-23. https://doi.org/10.1080/00222933.2011.622055

Decru E., Moelants T., De Gelas K., Vreven E., Verheyen E. \& Snoeks J. 2016. Taxonomic challenges in freshwater fishes: a mismatch between morphology and DNA barcoding in fish of the north-eastern part of the Congo Basin. Molecular Ecology Resources 16: 342-352. https://doi.org/10.1111/1755-0998.12445

Decru E., Vranken N., Bragança P.H.N., Snoeks J. \& Van Steenberge M. 2019. Where ichthyofaunal provinces meet: the fish fauna of the Lake Edward system, East Africa. Journal of Fish Biology 96 (5): 1186-1201. https://doi.org/10.1111/jfb.13992

Froese R. \& Pauly D. (eds) 2018. FishBase. Available from www.fishbase.org [accessed 21 Nov. 2018]. Froese R. \& Pauly D. (eds) 2019. FishBase. Available from www.fishbase.org [accessed 6 Nov. 2019].

Greenwood P.H. 1962. A revision of certain Barbus (Pisces, Cyprinidae) from East, Central and South Africa. Bulletin of the Natural History Museum, Zoology series 8 (4): 151-208. Available from https://www.biodiversitylibrary.org/part/118628\#/summary [accessed 21 Nov. 2018].

Greenwood P.H. 1966. The Fishes of Uganda. The Uganda Society, Kampala.

Greenwood P.H. 1970. A revision of the cyprinid species Barbus (Enteromius) radiatus Peters, 1853, with a note on the synonymy of the subgenera Beirabarbus and Enteromius. Revue de Zoologie et de Botanique africaines 82: 1-13.

Hayes M.M. \& Armbruster J.W. 2017. The taxonomy and relationships of the African small barbs (Cypriniformes: Cyprinidae). Copeia 105 (2): 348-362. https://doi.org/10.1643/CI-15-348

Hebert P.D.N., Cywinska A., Ball S.L. \& deWaard J.R. 2003. Biological identifications through DNA barcodes. Proceedings of the Royal Society of London B. Biological Sciences 270: 313-321. https://doi.org/10.1098/rspb.2002.2218

Howes G.J. 1991. Systematics and biogeography: an overview. In: Winfield I.J. \& Nelson J.S. (eds) Cyprinid Fishes: Systematics, Biology and Exploitation: 1-33. Chapman \& Hall, London, UK.

Ivanova N.V., Zemlak T.S., Hanner R.H. \& Hebert P.D. 2007. Universal primer cocktails for fish DNA barcoding. Molecular Ecology Notes 7: 544-548. https://doi.org/10.1111/j.1471-8286.2007.01748.x

Kassambara A. \& Mundt F. 2017. Factoextra: extract and visualize the results of multivariate data analyses. R package version 1.0.5. Available from https://CRAN.R-project.org/package=factoextra [accessed 1 Apr. 2020].

Katemo Manda B., Snoeks J., Decru E., Bills R. \& Vreven E. 2019. Enteromius thespesios (Teleostei: Cyprinidae): a new minnow species with a remarkable sexual dimorphism from the south-eastern part of the Upper Congo River. Journal of Fish Biology 96 (5): 1160-1175. https://doi.org/10.1111/jfb.14108

Kumar S., Stecher G. \& Tamura K. 2016. MEGA7: Molecular Evolutionary Genetics Analysis version 7.0 for bigger datasets. Molecular Biology and Evolution 33: 1870-1874.

https://doi.org/10.1093/molbev/msw054

Leigh J.W. \& Bryant D. 2015. POPART: full-feature software for haplotype network construction. Methods in Ecology and Evolution 6: 1110-1116. https://doi.org/10.1111/2041-210X.12410

Levin B.A., Dgebuadze Y.Y., Tefera F., Tesfaye G. \& Golubtsov A.S. 2017. An evidence of past introgressive hybridization between Labeobarbus ethiopicus and L. intermedius in the Ethiopian Rift Valley, East Africa. Ethiopian Journal of Biological Sciences 16 (Suppl.): 45-60.

Lowe-McConnell R.H. 1975. Fish Communities in Tropical Freshwaters. Longman, New York, USA. 
Manly B.F.J. 1994. Multivariate Statistical Methods: A Primer. $2^{\text {nd }}$ Ed. Chapman \& Hall, Boca Raton, Florida, USA.

Mbalassa M., Bagalwa J.J.M., Nshombo M. \& Kateyo M.E. 2014. Assessment of physicochemical parameters in relation with fish ecology in Ishasha River and Lake Edward, Albertine Rift Valley, East Africa. International Journal of Current Microbiology and Applied Sciences 3(6): 230-244.

Mipounga H.K., Cutler J., Beh J.H.M., Adam B. \& Sidlauskas B.L. Enteromius pinnimaculatus sp. nov. (Cypriniformes: Cyprinidae) from southern Gabon. Journal of Fish Biology 96 (5): 1218-1233. https://doi.org/10.1111/jfb.13995

Ndeda V.M., Mateos M. \& Hurtado L. 2018. Evolution of African barbs from the Lake Victoria drainage system, Kenya. PeerJ 6: e5762. https://doi.org/10.7717/peerj.5762

Nelson J.S., Grande T.C. \& Wilson M.V.H. 2016. Fishes of the World. $5^{\text {th }}$ Ed. John Wiley \& Sons, Hoboken, New Jersey. https://doi.org/10.1002/9781119174844

Okaronon J.O., Katunzi E.F.B. \& Asila A.A. 1997. Fish Species Identification Guide for Lake Victoria, Enumerator's Field Guide. Lake Victoria Fisheries Research Project Phase II, Technical Document 1, Jinja, Uganda. Available from http://aquaticcommons.org/4150/ [accessed 21 Nov. 2018].

Oksanen J., Blanchet F.G., Friendly M., Kindt R., Legendre P., McGlinn D., Minchin P.R., O'Hara R.B., Simpson G.L., Solymos P., Stevens M.H.H., Szoecs E. \& Wagner H. 2018. Vegan: Community Ecology Package. R package version 2.5-2. Available from https://CRAN.R-project.org/package=vegan [accessed 31 Aug. 2019].

Poll M. 1939. Poissons. Exploration du Parc National Albert. Mission G.F. de Witte (1933-1935) fasc. 24: 1-81. Available from http://www.apncb.be/missions/mission-scientifique-au-parc-national-albert-de [accessed 8 Jun. 2018].

R Core Team. 2018. R: A Language and Environment for Statistical Computing. R Foundation for Statistical Computing, Vienna, Austria. Available from https://www.R-project.org/ [accessed 29 Feb. 2020].

Ren Q. \& Mayden R.L. 2016. Molecular phylogeny and biogeography of African diploid barbs, 'Barbus', and allies in Africa and Asia (Teleostei: Cypriniformes). Zoologica Scripta 45 (6): 642-649. https://doi.org/10.1111/zsc.12177

Rice W.R. 1989. Analyzing tables of statistical tests. Evolution 43 (1): 223-225. https://doi.org/10.1111/j.1558-5646.1989.tb04220.x

Roberts T.R. 1975. Geographical distribution of African freshwater fishes. Zoological Journal of the Linnean Society 57: 249-319. https://doi.org/10.1111/j.1096-3642.1975.tb01893.x

RStudio Team. 2016. RStudio: Integrated Development for R. RStudio Inc., Boston, MA. Available from http://www.rstudio.com/ [accessed 3 Jul. 2020].

Scharpf C. \& Lazara K.J. 2019. The ETYFish Project. Available from www.etyfish.org [accessed 17 Sep. 2019].

Schmidt R.C., Bart Jr. H.L. \& Nyingi W.D. 2017. Multi-locus phylogeny reveals instances of mitochondrial introgression and unrecognized diversity in Kenyan barbs (Cyprininae: Smiliogastrini). Molecular Phylogenetics and Evolution 111: 35-43. https://doi.org/10.1016/j.ympev.2017.03.015

Schmidt R.C., Bart Jr. H.L. \& Nyingi W.D. 2018. Integrative taxonomy of the red-finned barb, Enteromius apleurogramma (Cyprininae: Smiliogastrini) from Kenya, supports recognition of E. amboseli as a valid species. Zootaxa 4482 (3): 566-578. https://doi.org/10.11646/zootaxa.4482.3.8 
Schmidt R.C., Dillon M.N., Kuhn N.M., Bart Jr. H.L. \& Pezold F. 2019. Unrecognized and imperilled diversity in an endemic barb (Smiliogastrini, Enteromius) from the Fouta Djallon highlands. Zoologica Scripta 48 (5): 605-613. https://doi.org/10.1111/zsc.12362

Schwarzer J., Swartz E.R., Vreven E., Snoeks J., Cotterill F.P.D., Misof B. \& Schliewen U.K. 2012. Repeated trans-watershed hybridization among haplochromine cichlids (Cichlidae) was triggered by Neogene landscape evolution. Proceedings of the Royal Society of London B. Biological Sciences 279 (1746): 4389-4398. https://doi.org/10.1098/rspb.2012.1667

Seegers L., De Vos L. \& Okeyo D.O. 2003. Annotated checklist of the freshwater fishes of Kenya (excluding the lacustrine haplochromines from Lake Victoria). Journal of East African Natural History 92: 11-47. https://doi.org/10.2982/0012-8317(2003)92\%5B11:ACOTFF\%5D2.0.CO;2

Seehausen O. \& Wagner C.E. 2014. Speciation in freshwater fishes. Annual Review of Ecology, Evolution, and Systematics 45: 621-651. https://doi.org/10.1146/annurev-ecolsys-120213-091818

Skelton P.H. 1994. Diversity and distribution of freshwater fishes in East and Southern Africa. Annals of the Royal Central Africa Museum (Zoology) 275: 95-131.

Skelton P.H., Tweddle D. \& Jackson P.B.N. 1991. Cyprinids of Africa. In: Winfield I.J. \& Nelson J.S. (eds) Cyprinid Fishes: Systematics, Biology and Exploitation: 211-239. Chapman \& Hall, London, UK.

Snoeks J. 2004. The Cichlid Diversity of Lake Malawi/Nyasa/Niassa: Identification, Distribution and Taxonomy. Cichlid Press, El Paso, USA.

Snoeks J., Harrison I.J. \& Stiassny M.L.J. 2011. The status and distribution of freshwater fishes. In: Darwall W.R.T., Smith K.G., Allen D.J., Holland R.A., Harrison I.J. \& Brooks E.G.E. (eds) The Diversity of Life in African Freshwaters: Under Water, Under Threat. An Analysis of the Status and Distribution of Freshwater Species throughout Mainland Africa: 42-73. IUCN, Cambridge \& Gland.

Templeton A.R., Crandall K.A. \& Sing C.F. 1992. A cladistic analysis of phenotypic associations with haplotypes inferred from restriction endonuclease mapping and DNA sequence data. III. Cladogram estimation. Genetics 132: 619-633.

Van Ginneken M., Decru E., Verheyen E. \& Snoeks J. 2017. Morphometry and DNA barcoding reveal cryptic diversity in the genus Enteromius (Cypriniformes: Cyprinidae) from the Congo basin, Africa. European Journal of Taxonomy 310: 1-32. https://doi.org/10.5852/ejt.2017.310

Wagner C.E., McCuneA.R. \& Lovette I.J. 2012. Recent speciation between sympatric Tanganyikan cichlid colour morphs. Molecular Ecology 21: 3283-3292. https://doi.org/10.1111/j.1365-294X.2012.05607.x

Whitehead P.J.P. 1960. Three new cyprinid fishes of the genus Barbus from the Lake Victoria basin. Revue de Zoologie et de Botanique africaines 62 (1-2): 106-119.

Yang L., Sado T., Hirt M.V., Pasco-Viel E., Arunachalam M., Li J., Wang X., Freyhof J., Saitoh K., Simons A.M., Miya M., He S. \& Mayden R.L. 2015. Phylogeny and polyploidy: resolving the classification of cyprinine fishes (Teleostei: Cypriniformes). Molecular Phylogenetics and Evolution 85: 97-116. https://doi.org/10.1016/j.ympev.2015.01.014

Manuscript received: 9 April 2020

Manuscript accepted: 23 June 2020

Published on: 11 August 2020

Topic editor: Rudy Jocqué

Section editor: Felipe Ottoni

Desk editor: Pepe Fernández 
Printed versions of all papers are also deposited in the libraries of the institutes that are members of the EJT consortium: Muséum national d'histoire naturelle, Paris, France; Meise Botanic Garden, Belgium; Royal Museum for Central Africa, Tervuren, Belgium; Royal Belgian Institute of Natural Sciences, Brussels, Belgium; Natural History Museum of Denmark, Copenhagen, Denmark; Naturalis Biodiversity Center, Leiden, the Netherlands; Museo Nacional de Ciencias Naturales-CSIC, Madrid, Spain; Real Jardín Botánico de Madrid CSIC, Spain; Zoological Research Museum Alexander Koenig, Bonn, Germany; National Museum, Prague, Czech Republic.

\section{Supplementary files}

SM.01. Overview of the specimens used for morphological and genetic analyses.

SM.02. PC loadings and percentages of total variance of the PCA on 24 log-transformed measurements of Enteromius Cope, 1867: group A $(\mathrm{n}=21)$ and group B $(\mathrm{n}=50)$.

SM.03. PC loadings and percentages of total variance of the PCA on 24 log-transformed measurements of Enteromius Cope, $1867(\mathrm{n}=69)$.

SM.04. PC loadings and percentages of total variance of the PCA on 15 meristics of Enteromius Cope, $1867(\mathrm{n}=62)$.

SM.05. PC loadings and percentages of total variance of the PCA on 24 log-transformed measurements of Enteromius Cope, $1867(\mathrm{n}=105)$.

SM.06. PC loadings and percentages of total variance of the PCA on 15 meristics of Enteromius Cope, $1867(\mathrm{n}=95)$.

SM.07. PC loadings and percentages of total variance of the PCA on 24 log-transformed measurements of Enteromius Cope, $1867(\mathrm{n}=83)$. 